\title{
Article \\ LPEATs Tailor Plant Phospholipid Composition through Adjusting Substrate Preferences to Temperature
}

\author{
Sylwia Klińska *[D, Kamil Demski ${ }^{*}{ }^{\dagger}$, Katarzyna Jasieniecka-Gazarkiewicz and Antoni Banaś \\ Intercollegiate Faculty of Biotechnology, University of Gdansk and Medical University of Gdansk, \\ 80-307 Gdansk, Poland; katarzyna.jasieniecka@biotech.ug.edu.pl (K.J.-G.); antoni.banas@biotech.ug.edu.pl (A.B.) \\ * Correspondence: sylwia.klinska@phdstud.ug.edu.pl (S.K.); kamil.demski@slu.se (K.D.) \\ + Present address: Department of Plant Breeding, Swedish University of Agricultural Sciences, \\ 23053 Alnarp, Sweden.
}

\begin{abstract}
Acyl-CoA:lysophosphatidylethanolamine acyltransferases (LPEATs) are known as enzymes utilizing acyl-CoAs and lysophospholipids to produce phosphatidylethanolamine. Recently, it has been discovered that they are also involved in the growth regulation of Arabidopsis thaliana. In our study we investigated expression of each Camelina sativa LPEAT isoform and their behavior in response to temperature changes. In order to conduct a more extensive biochemical evaluation we focused both on LPEAT enzymes present in microsomal fractions from C. sativa plant tissues, and on cloned CsLPEAT isoforms expressed in yeast system. Phylogenetic analyses revealed that CsLPEAT1c and CsLPEAT2c originated from Camelina hispida, whereas other isoforms originated from Camelina neglecta. The expression ratio of all CsLPEAT1 isoforms to all CsLPEAT2 isoforms was higher in seeds than in other tissues. The isoforms also displayed divergent substrate specificities in utilization of LPE; CsLPEAT1 preferred 18:1-LPE, whereas CsLPEAT2 preferred 18:2-LPE. Unlike CSLPEAT1, CsLPEAT2 isoforms were specific towards very-long-chain fatty acids. Above all, we discovered that temperature strongly regulates LPEATs activity and substrate specificity towards different acyl donors, making LPEATs sort of a sensor of external thermal changes. We observed the presented findings not only for LPEAT activity in plant-derived microsomal fractions, but also for yeast-expressed individual CsLPEAT isoforms.
\end{abstract}

Keywords: LPEAT; LPLAT; phospholipid; abiotic stress; heat stress; cold stress; Camelina sativa

Academic Editor: Abir

U. Igamberdiev

Received: 30 June 2021

Accepted: 27 July 2021

Published: 29 July 2021

Publisher's Note: MDPI stays neutral with regard to jurisdictional claims in published maps and institutional affiliations.

\section{Introduction}

Terrestrial plants are continually subjected to diverse environmental stimuli. One of the biggest challenges facing worldwide flora is exposure to a broad range of temperatures. Current ambient temperature conditions are characterized by frequent fluctuations and constant increase due to climate change. High and low temperatures may cause diverse detrimental effects on plant physiology, e.g., the inhibition of protein folding or its enzymatic activity, increase in oxidative stress and ROS generation, and impairment of photosynthesis. This may ultimately lead to reduced plant growth, yield, or even cell death [1]. Both heat and cold also influence cell membrane fluidity. Proper membrane structure is required to maintain homeostasis and protect the membrane itself and its proteins from deleterious temperature effects [2-4]). The upkeep of membrane fluidity appropriate to surrounding environmental conditions is mainly regulated by phospholipids and their structure: either a liquid crystalline or a solid phase (also known as gel phase). Liquid structure is promoted by low temperature and is composed by unsaturated fatty acids, whereas solid phase is promoted by heat stress and favors saturated and long-chain fatty acids [5]. One of the major phospholipids composing cell membranes is phosphatidylethanolamine (PE).

$\mathrm{PE}$ is one of the main eukaryotic membrane-building components, constituting-together with phosphatidylcholine (PC) approximately $50 \%$ of all cellular phospholipids [6,7]. Much 
research has provided significant information regarding PE's physiological role in prokaryotic and eukaryotic cells. PE may be crucial in spatial structure formation, by creating hexagonal structures [8], maintaining the proper activity of yeast respiratory system and controlling the correct structure, folding, and activity of peripheral membrane proteins [9]. PE-derivatives also play a pivotal role as second messengers [10]. Additionally, Rockenfeller et al. [11] reported that high levels of PE may positively regulate autophagy process and prolong longevity in yeast and flies. Other studies established the essential role of PE in cell death via DHA-dependent pathway and via ferroptosis $[12,13]$.

In eukaryotic cells, three different pathways of PE synthesis can be distinguished. The compound is synthesized mainly via the CDP-ethanolamine pathway including three successive reactions described by Kennedy and Weiss [14]. First, PE is phosphorylated by ethanolamine kinase (EK) in ATP-dependent reaction. Subsequently, PE is conjugated with CTP to form a high-energy donor-CDP-ethanolamine. This step is catalyzed by CTP:phosphoethanolamine cytidyltransferase (ECT). The last reaction is conducted by CDP-ethanolamine:1,2-diacylglycerol ethanolaminephosphotransferase (EPT) responsible for transferring ethanolamine from CDP-ethanolamine to $s n-3$ position of diacylglycerol, providing a final product-phosphatidylethanolamine. The second possible way of PE biosynthesis is via the phosphatidylserine decarboxylase (PSD) activity, where serine is converted into ethanolamine by detachment of a carboxyl group [15]. The biosynthesis of PE in plant cells may also occur via acyl-CoA: lysophosphatydylethanolamine acyltransferases activity (LPEAT; [16]).

The biochemical role of LPEAT (a representative of acyl-CoA:lysophospholipid acyltransferases-LPLATs) is to transfer acyl group from a cytosolic pool of acyl-CoA to lysophosphatydylethanolamine, producing PE [17]. LPLAT enzymes can also conduct reverse reactions supplying acyl pool with newly modified/synthesized fatty acids, therefore playing an essential role in acyl editing. PC-synthesizing LPCAT (acyl-CoA:lysofosfatydylcholine acyltransferases) enzymes are recognized as major contributors to the acyl editing process (and subsequently to the storage lipid composition) both through their forward and reverse actions [18] (Bates et al. 2012). The substrate specificity and efficiency of both LPLAT reactions may significantly vary $[19,20]$. In case of LPEAT enzymes present in Camelina sativa seeds, their contribution to the remodeling of acyl-CoA pool is rather small compared to the activity of LPCAT (acyl-CoA:lysofosfatydylcholine acyltransferases) enzymes, which seems to play a major role in this process. Deacylation activity of LPLAT enzymes may also be effectively supported by phospholipase $A_{2}$ in a process called Land's cycle [21] as well as with PDAT (phospholipid:diacylglycerol acyltransferases) type of enzymes [22].

The knowledge about plant LPLAT enzymes is still insufficient to fully understand their biochemical and physiological role. Their main function is the regulation of the composition of phospholipid molecular species present in cell membranes. Therefore, they are responsible for maintaining proper membrane fluidity, structure, and vesicle trafficking [23]. Until now, most studies have focused on LPCAT or LPAAT (acyl-CoA:lysophosphatidic acid acyltransferases) enzymes, which synthesize phosphatidylcholine and phosphatidic acid, respectively.

LPEAT enzymes were first characterized in Arabidopsis thaliana. In 2009, two genes, At1g80950 and At2g45670, were recognized as genes encoding proteins with LPEAT activity: LPEAT1 and LPEAT2 isoenzymes [16]. Later studies concerning their physiological role revealed that both genes are necessary for proper growth and development. The T-DNA insertion mutant lpeat 2 and double mutant (lpeat 1 lpeat2) of $A$. thaliana were characterized by impaired growth, shorter roots, smaller leaves, and reduced lipid content; especially, the content of PE was lowered. The opposite morphological results were observed for overexpressors [24]. Furthermore, recent study demonstrated that inhibiting LPEAT activity may prolong plant lifespan and delay the senescence process [25].

Despite the much smaller contribution of LPEAT compared to LPCAT in acyl-CoA pool editing, these enzymes may hold key roles in other significant physiological processes. In the presented research, we propose a new physiological role of LPEAT enzymes: re- 
sponding to temperature variations with modifications of the membrane phospholipid make-up. In in vitro assays, we found changes in the substrate specificity of LPEATs (present in microsomal fractions derived from different vegetative and generative tissues) subjected to various temperature conditions. Additionally, we established the expression of each homeolog encoding LPEAT1 and LPEAT2 isoenzymes. Furthermore, we undertook the challenge of cloning genes encoding LPEAT enzymes' homeologs from a hexaploid plant (Camelina sativa). Isolated genes encoding appropriate variants of LPEAT isoenzymes were biochemically characterized to determine both their specificity towards different fatty acid donors (acyl-CoAs) and acceptors (lysolipids), and how their properties are influenced by thermal conditions.

\section{Results}

2.1. Temperature Alters Acyl-CoA Specificity of LPEAT Enzymes Present in Vegetative Tissues

To establish the influence of temperature on acyl-CoA specificities of LPEAT enzymes, we used microsomal fractions isolated from different tissues: one generative (seeds) and three vegetative (leaves cultivated in vitro, leaves cultivated in vivo, and roots cultivated in vitro). The studied temperature ranged between $10^{\circ} \mathrm{C}$ and $40^{\circ} \mathrm{C}$. Prior to major analysis, optimization in the search of the best parameters for enzymatic in vitro reaction was carried out. In case of seeds optimal reaction parameters were determined in previous study done by Klińska et al. [26]. For vegetative tissues, this optimization was conducted on microsomal fractions derived from in vivo leaves. Based on both evaluations the chosen in vitro reaction parameters were microsomal fraction equivalent to $0.5 \mathrm{nmol}$ of endogenous PC per assay, a reaction time of $60 \mathrm{~min}$ and buffer $\mathrm{pH}$ equal to 7.2. The chosen $\mathrm{pH}$ corresponds to $\mathrm{pH}$ in plant endoplasmic reticulum [27] and was chosen despite the fact that for in vivo leaves optimal $\mathrm{pH}$ value was 9.0 and for seeds the optimal $\mathrm{pH}$ value stretched between 9.0 and 10.0 (Supplementary Figure S1; [28]. We decided to evaluate LPEAT acyl-CoA specificity with 5 substrates: 16:0-CoA, 18:0-CoA, 18:1-CoA, 18:2-CoA, and 18:3-CoA. Acyl-CoAs we picked constitute the most common group of fatty acids found in PE pools of various plant tissues.

Taking into account all accumulated results presented in Figure 1, we noticed that activity towards 18:2-CoA was the highest regardless of the tissue analyzed. The only divergence occurred in regard to temperature. LPEAT reached the highest activity (towards 18:2-CoA) at $30^{\circ} \mathrm{C}$ for vegetative tissue and at $20{ }^{\circ} \mathrm{C}$ for seeds. The enzyme showed the least specificity towards 18:0-CoA. The preference towards the 18:0 acyl group reached at most $11 \%$ (except microsomal fractions from in vivo leaves where this value rose to about $23 \%$ ) of the LPEAT activity towards 18:2-CoA. Temperature change did not affect the enzyme's overall activity drastically. The top values, however, were obtained at $30^{\circ} \mathrm{C}$ for each analyzed tissue. 

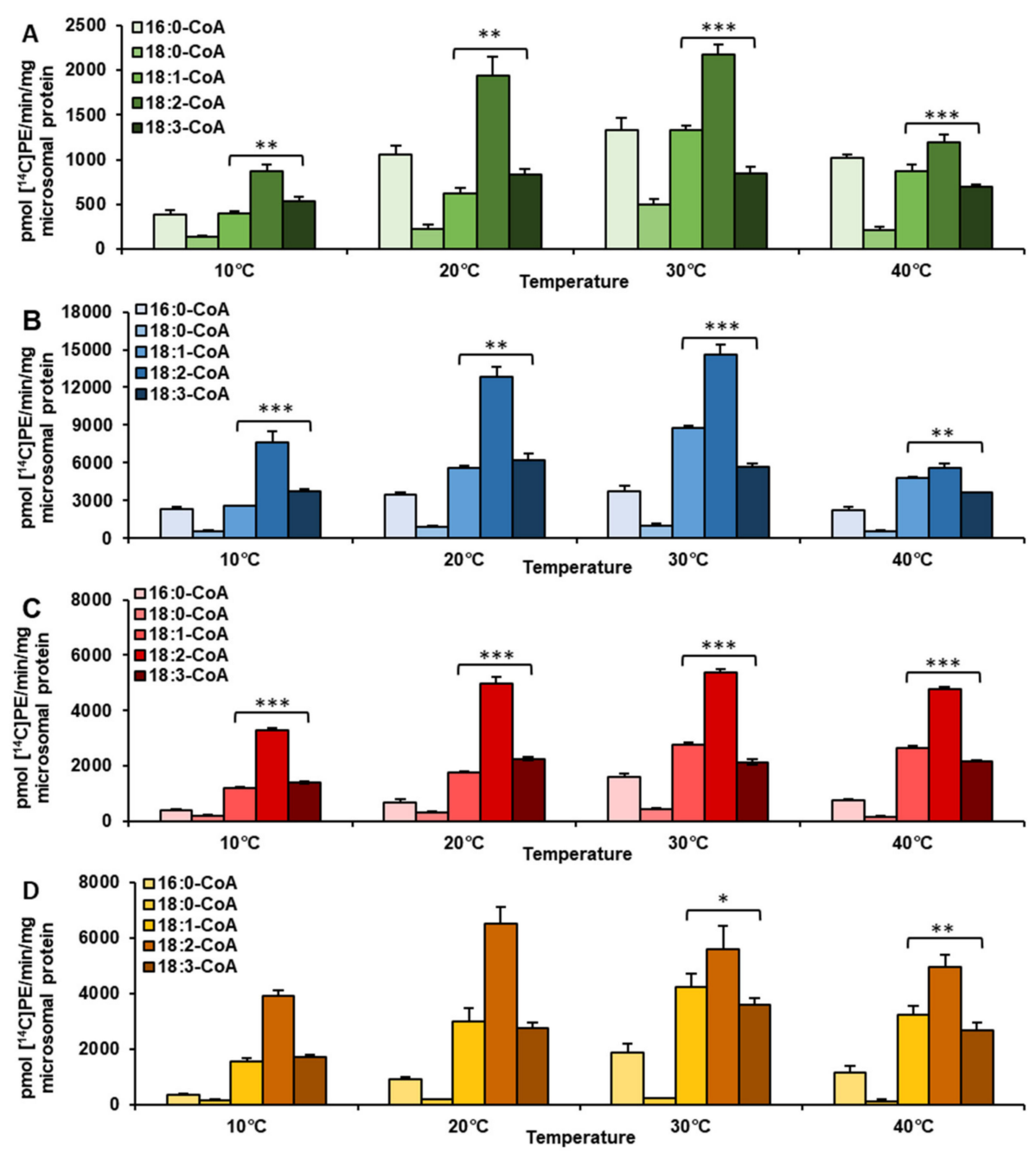

Figure 1. Activity of acyl-CoA:lysophospatidylethanolamine acyltransferases (LPEATs) present in microsomal fractions of Camelina sativa tissues towards five acyl-CoAs at different temperatures. ((A) —in vivo leaves; (B) - in vitro leaves; (C)—n vitro roots; (D)—seeds). Mean values and SD are presented (data from at least three independent assays). Asterisks denote significant differences between activity towards 18:1-CoA and 18:3-CoA at different temperatures in a mean difference two-sided Student's t test: ${ }^{*} p \leq 0.05 ;{ }^{* *} p \leq 0.01 ;{ }^{* * *} p \leq 0.001$.

LPEAT enzymes present in in vivo leaves exhibited elevated preference (compared to other analyzed tissues) not only towards 18:0-CoA (see above) but also towards 16:0-CoA. At 20,30 , and $40{ }^{\circ} \mathrm{C}$ it was the second most favored acyl donor. LPEAT activity with 16:0-CoA reached respectively: $54.4 \%, 60 \%$ and $84.7 \%$ of its activity towards $18: 2-\mathrm{CoA}$, at the aforementioned temperatures (Figure 1A).

In other tested tissues, LPEAT preferred 18:1-CoA and 18:3-CoA over 16:0-CoA. Which of the two acyl-CoAs LPEAT was more specific towards depended on temperature. This was especially true in vegetative tissues. At 10 and $20^{\circ} \mathrm{C}$ LPEAT enzymes from vegetative tissues preferentially utilized 18:3-CoA with the efficiency ranging between 111 and $146 \%$ of LPEAT activity towards 18:1-CoA. The results were opposite at higher tested temperatures, where 18:1-CoA was more favored by LPEAT enzymes. LPEAT activity with 18:1-CoA reached about $120-130 \%$ of LPEAT activity with $18: 3-\mathrm{CoA}$ at $40^{\circ} \mathrm{C}$. At $30^{\circ} \mathrm{C}$ the differences were even bigger and oscillated between 130 and 158\% of LPEAT activity towards 18:3-CoA (Figure 1A-C). Such fluctuations in preference towards oleic and linolenic acids were also noticed in seeds, however only at 30 and $40{ }^{\circ} \mathrm{C}$. At these temperatures LPEAT activity with 18:3-CoA achieved only between 77 and $85 \%$ of its activity towards 18:1-CoA (Figure 1D). 
Not only LPEAT, but also LPCAT enzymes are able to synthesize phosphatidylethanolamine to some extent [20]. To exclude the possibility that the observed effects were a result of LPCAT enzymes activity, we conducted LPCAT substrate specificity assays towards various acyl donors at different temperatures in two different tissues (in vivo leaves and in vitro roots). The LPEAT-like trend of substrate specificity changing with reaction temperature could not be observed for LPCAT enzyme assays. Both analyzed enzymes exhibited a distinct pattern of substrate specificity towards tested acyl donors (Figure 1; Supplementary Figure S2).

The lowest activity of LPEAT enzymes, for all tested acyl donors, was detected in microsomal fractions prepared from in vivo leaves. The highest LPEAT activity was observed for in vitro leaves. For example, LPEAT activity towards 18:2-CoA in in vitro leaves was 6.6 times higher in comparison to in vivo leaves at 20 and $30^{\circ} \mathrm{C}$. At $10^{\circ} \mathrm{C}$ the difference between the tissues was even more pronounced-8.8 times higher. However, at $40{ }^{\circ} \mathrm{C}$, LPEAT activity in in vitro leaves was only 4.7 times higher than in leaves in vivo (Figure 1A,B).

Microsomal fractions from both kinds of leave tissues were used in substrate selectivity assays to verify the results observed in single acyl-CoA assays, described above. The assays were conducted at 10 and $30^{\circ} \mathrm{C}$-temperatures at which significant changes in substrate specificity of LPEAT were observed. BSA was added to enzyme assays to replace the naturally occurring acyl-CoA binding protein (ACBP). In these assays LPEAT enzymes from microsomal fractions of in vivo leaves, showed almost equal preference towards 18:1CoA and 18:2-CoA, regardless of temperature. The activity towards 16:0-CoA, 18:0-CoA and 18:3-CoA at $30{ }^{\circ} \mathrm{C}$ was almost equal and accounted for about $30 \%$ of that towards 18:2-CoA. At $10^{\circ} \mathrm{C}$ relative affinity towards 18:0-CoA remained similar, whereas towards 16:0-CoA and 18:3-CoA increased to around $50 \%$ of the relative affinity towards $18: 2-\mathrm{CoA}$ (Figure 2B). The changes in acyl-CoA preferences of LPEAT enzymes from microsomal fractions of in vitro leaves were less pronounced than those described above. However, also in these assays, the preferences of LPEAT enzymes towards 18:1-CoA were more elevated compared to single acyl-CoA assays especially at $30^{\circ} \mathrm{C}$. At that temperature the LPEATs activity towards $18: 1-\mathrm{CoA}$ reached about $145 \%$ of that towards $18: 2-\mathrm{CoA}$. The relative activity towards $18: 3-\mathrm{CoA}$ compared to $18: 2-\mathrm{CoA}$ was somewhat similar like in single acyl-CoA assays with somewhat higher affinity to $18: 3-\mathrm{CoA}$ at $10{ }^{\circ} \mathrm{C}$ compared to $30^{\circ} \mathrm{C}$. Unlike in single acyl-CoA assays the LPEAT affinity towards 16:0-CoA and 18:0-CoA was similar and at $10{ }^{\circ} \mathrm{C}$ accounted for about $20 \%$ of the LPEAT affinity towards 18:2-CoA, whereas at $30{ }^{\circ} \mathrm{C}$ their activity raised to $59 \%$ and $43 \%$, respectively (Figures $1 \mathrm{~A}$ and $2 \mathrm{~A}$ ).
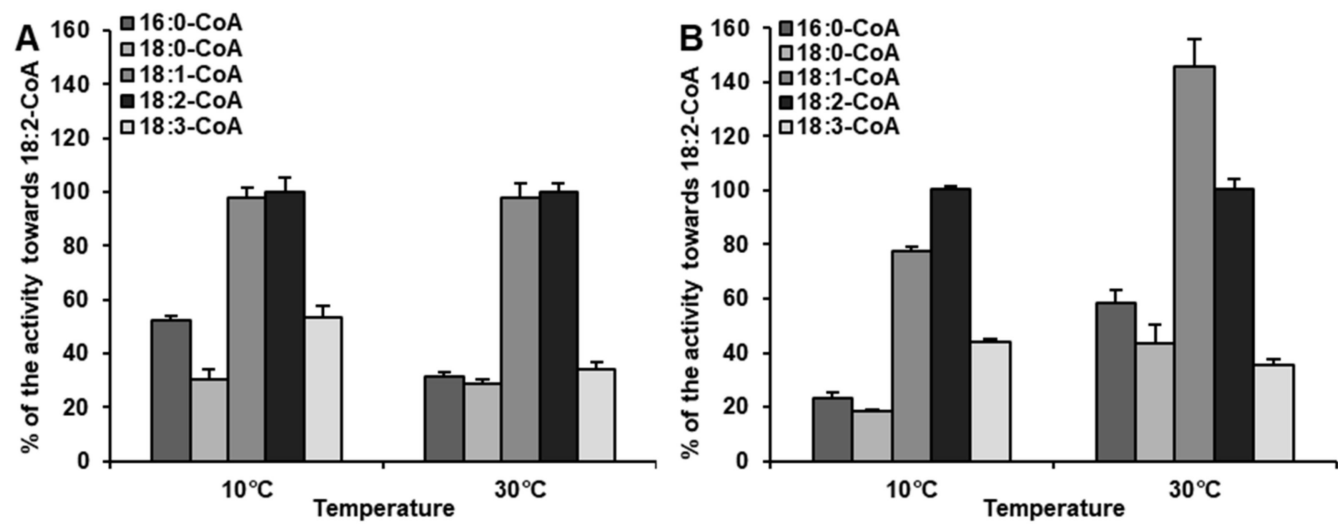

Figure 2. Activity of acyl-CoA:lysophospatidylethanolamine acyltransferases (LPEATs) present in microsomal fraction of Camelina sativa derived from in vivo (A) and in vitro (B) leaves towards five various acyl-CoAs added in equimolar concentrations with BSA into the reaction mixture. Mean values and SD are presented (data from at least three independent assays). 
Additionally, we conducted assays determining the rate of incorporation of fatty acids from acyl-CoA pool to PE of microsomal fractions of in vivo leaves. Using these results, we also estimated the time of complete fatty acid turnover in PE. The assays were conducted in two extreme temperatures: 10 and $40{ }^{\circ} \mathrm{C}$. In such assays, fatty acids from acyl-CoA pool were incorporated into lyso-PE (LPE) via LPEAT action and PE with new set of fatty acids was created. In the assay conditions we used, the LPE available for LPEAT is formed via phospholipase A activity, via PDAT activiaty and via the reverse reaction of LPEAT enzymes. Thus, the results constitute the rate of fatty acids remodeling of PE with participation of all of the above mentioned types of reactions. The observed intensity of remodeling of fatty acids of PE was from 2.7 to 4.9 times faster at $40{ }^{\circ} \mathrm{C}$ than at $10^{\circ} \mathrm{C}$. The biggest difference was observed, if 18:2-CoA was used in the assays and the lowest difference was observed, if $18: 3-\mathrm{CoA}$ was used. At $10^{\circ} \mathrm{C}$, the estimated complete turnover of PE fatty acids took about 7,9 , and 14 days and at $40{ }^{\circ} \mathrm{C}$ about 2,2 , and 5 days for 18:1-CoA, 18:2-CoA and 18:3-CoA fatty acid donors, respectively (Table 1).

Table 1. Incorporation rate of $\left[{ }^{14} \mathrm{C}\right]$ acyl groups from $\left[{ }^{14} \mathrm{C}\right] \mathrm{acyl}-\mathrm{CoA}$ into PE of microsomal fractions of Camelina sativa in vivo leaves and estimated time of complete exchange of acyl groups of PE for fatty acids from acyl-CoA pool. Mean values and SD are presented (data from at least three independent assays).

\begin{tabular}{cccc}
\hline Temperature & $\begin{array}{c}\text { Acyl-CoA Used in } \\
\text { the Assay }\end{array}$ & $\begin{array}{c}\left.\text { pmol [ }{ }^{14} \mathrm{C}\right] \mathrm{PE} / \mathbf{n m o l} \\
\text { Microsomal PE/min] }\end{array}$ & $\begin{array}{c}\text { Time of Exchange of All } \\
\text { PE Fatty Acids (FA) for } \\
\text { FA from Acyl-CoA } \\
\text { Pool [Days] }\end{array}$ \\
\hline \multirow{3}{*}{$10^{\circ} \mathrm{C}$} & {$\left[{ }^{14} \mathrm{C}\right] 18: 1-\mathrm{CoA}$} & $0.194 \pm 0.03$ & 7.2 \\
& {$\left[{ }^{14} \mathrm{C}\right] 18: 2-\mathrm{CoA}$} & $0.155 \pm 0.004$ & 8.9 \\
& {$\left[{ }^{44} \mathrm{C}\right] 18: 3-\mathrm{CoA}$} & $0.101 \pm 0.005$ & 13.8 \\
$40{ }^{\circ} \mathrm{C}$ & {$\left[{ }^{4} \mathrm{C}\right] 18: 1-\mathrm{CoA}$} & $0.711 \pm 0.03$ & 2.0 \\
& {$\left[{ }^{14} \mathrm{C}\right] 18: 2-\mathrm{CoA}$} & $0.763 \pm 0.007$ & 1.8 \\
& {$\left[{ }^{14} \mathrm{C}\right] 18: 3-\mathrm{CoA}$} & $0.295 \pm 0.02$ & 5.1 \\
\hline
\end{tabular}

Next, we determined the fatty acid composition of sn- 1 and sn-2 positions in PE of Camelina sativa in vivo leaves. At the sn-1 palmitic acid (16:0) was the most dominant fatty acid, followed by linolenic (18:3) and linoleic (18:2) acids, accounting for respectively 60 , 15 , and $13 \%$ of all fatty acids present at sn- 1 position. The relative amounts of $18: 0$ and 18:1 accounted for about 8 and $4 \%$, respectively. The most abundant acyl groups at sn-2 position were polyunsaturated fatty acids $18: 3$ and 18:2 followed by 16:0-53, 30 and 10\%, respectively (Figure 3).

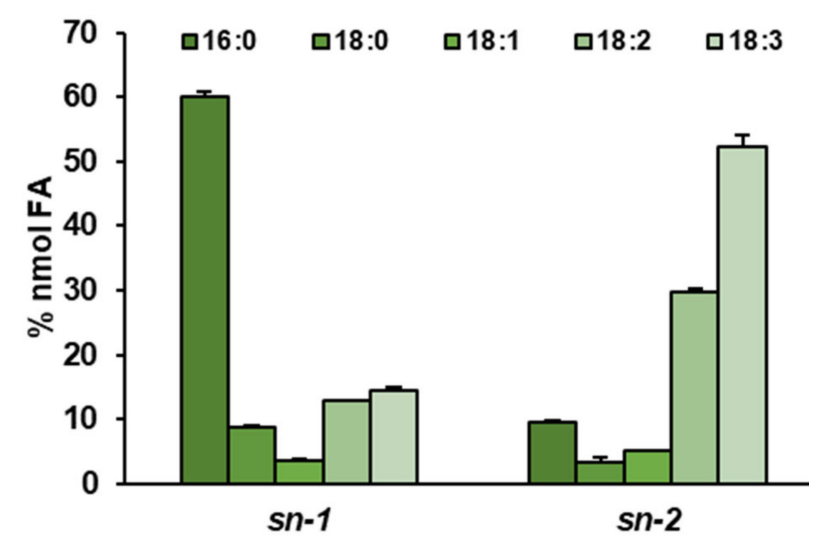

Figure 3. Fatty acids composition of $s n-1$ and $s n-2$ position in phosphatidylethanolamine isolated from C. sativa in vivo leaves. Error bars indicate the SD between the three biological repeats $(n=3)$. 


\subsection{Evolutionary Analyses Reveal Ancestral Origins of Camelina sativa LPEATs}

Hexaploid Camelina sativa genome constitutes of three merged subgenomes. Two of them are a result of an auto-hybridization event between Camelina neglecta-like plants. The third subgenome appeared through hybridization of the aforementioned auto-allotetraploid and Camelina hispida [29]. We conducted evolutionary analyses of the amplified CsLPEAT isoforms (as well as of reference CsLPEAT1b and CsLPEAT1c) and other LPEATs of Brassicaceae family (Figure 4). Both generated CsLPEAT1 and CsLPEAT2 trees revealed that most likely CsLPEAT1c and CsLPEAT2c are isoforms belonging to the Camelina hispidaoriginated subgenome, since they are more distantly related to the other two isoforms of their respective CsLPEAT.
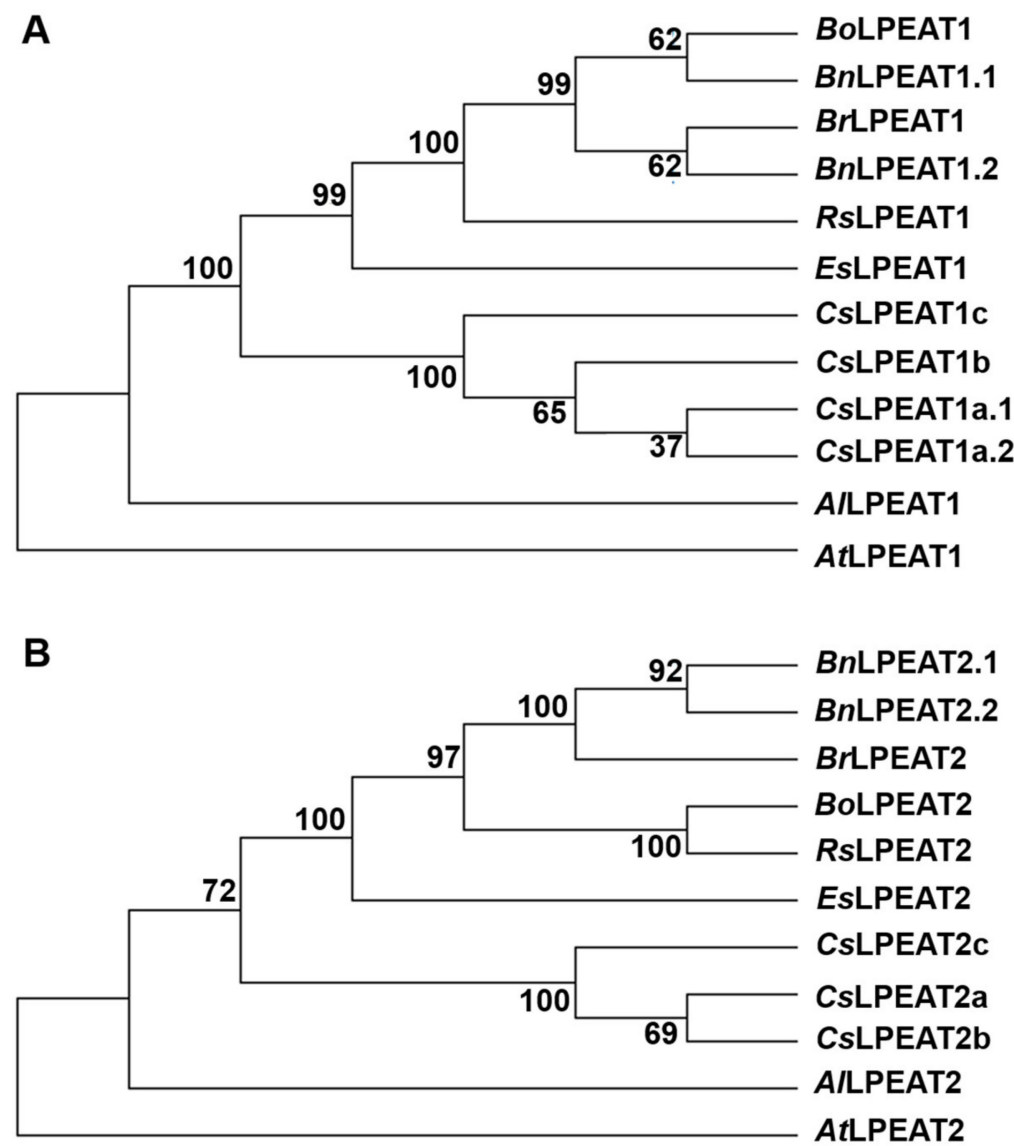

Figure 4. Predicted evolutionary relations between Brassicaceae family LPEATs. CsLPEAT1 isoforms and other LPEAT1 plant amino acid sequences are analyzed in panel (A), while CsLPEAT2 isoforms and other LPEAT2 plant amino acid sequences are analyzed in panel (B). Both trees are rooted in the corresponding Arabidopsis thaliana (At) orthologues (AtLPEAT1 for panel A, AtLPEAT2 for panel (B)). All gene denotations and their species of origin are elaborated on in Supplementary Table S4.

A conserved domain search [30] of the CSLPEAT protein sequences, showed that all isoforms possessed LPE-binding domains. Additionally, CsLPEAT2 isoforms all had calcium-binding domains, characteristic of proteins participating in calcium cell signaling pathways (Supplementary Figures S3 and S4). Biochemical assays estimating the effects of calcium ions on activity of microsomal fraction LPEATs of C. sativa seeds, however, showed that the addition of these ions to the reaction mixture does not stimulate enzyme activity and even showed some inhibitory effects [26]. Thus, the assays performed in this study were not supplemented with calcium ions. Amino acid sequence comparisons revealed only minor differences between the sequences; the lowest similarity was observed 
between CsLPEAT2a and CsLPEAT2c and between CsLPEAT2b and CsLPEAT2c (which have predicted distinct origin). Protein sequences of CsLPEAT1a.1 and CsLPEAT1a.2 showed differences only in three amino acid positions. One of them indicted a replacement of phenylalanine to cysteine near the active site, in the area where LPE-binding domain is present (Supplementary Table S1; Supplementary Figures S3 and S4).

\subsection{CsLPEAT1 and CsLPEAT2 Genes Expression Differs between Plant Tissues}

In order to determine the expression patterns of all six CsLPEAT1 and CsLPEAT2 isoforms in various plant tissues, we conducted both absolute (Figure 5A,D,G,J) and relative (Figure 5B,C,E,F,H-J,L) expression analyses. In case of most isoforms, patterns of absolute and relative expression were similar to each other, except for CsLPEAT1c, whose expression seemed to be higher, when determined utilizing relative quantifications. In most cases CsLPEAT1a (corresponding to its predicted variants CsLPEAT1a.1 and CsLPEAT1a.2) was the highest expressed CsLPEAT1 isoform, and CsLPEAT2b was the highest expressed CsLPEAT2 isoform. CsLPEAT1b was the least expressed CsLPEAT1 isoform in all the tissues, and CsLPEAT2c was the least expressed CsLPEAT2 isoform. What is clear from the obtained expression patterns is the substantially higher ratio of expression of all CsLPEAT1 isoforms over all CsLPEAT2 isoforms in seeds, in comparison to other tissues. CsLPEAT2b, the highest expressed CsLPEAT2 isoform, is the dominant isoform out of both CsLPEAT1 and CsLPEAT2 in in vivo leave tissue, especially when we only consider relative expression. Regarding only absolute expression, all CsLPEAT1 and CsLPEAT2 isoforms are most abundant in root tissue. Roots for this experiment were cultivated in vitro, as was leaves' tissue analyzed in panels D, E, and F. In comparison to CsLPEATs expression in in vitro leaves, CsLPEATs expression in in vitro roots is twice as high.

\subsection{Diverse Acyl-CoA Utilization by CsLPEAT Enzymes at Various Temperatures}

The sequences of the five discovered CSLPEAT genes were expressed in a haploid knock-out mutants of $\triangle A L E$ yeast strain deficient in PE synthesis via LPLAT activity, to determine their properties and activity at different temperatures. The transformation revealed that all CsLPEAT enzymes/isoforms were able to complement this type of deficiency of PE synthesis in the utilized $\triangle A L E$ mutant (Supplementary Figure S5).

After confirming their ability to synthesize PE via LPEAT action, the assays' conditions were optimized to define their properties in in vitro enzymatic reactions. Each of the tested CsLPEAT isoforms exhibited distinct preferences for the amount of microsomal fraction and reaction time (Supplementary Figures S6 and S7). The obtained results were applied in further analyses, where activity towards five acyl-CoAs at different temperatures was determined, utilizing 18:1-LPE as an acceptor of acyl groups (Figure 6). Moreover, we did a percentage estimation for the most preferred acyl donor (16:0-CoA) and two other acyl donors-ones which showed the biggest variability (18:1-CoA and 18:2-CoA). The activities of the enzymes were presented as the percentage of their respective CsLPEAT2b activity-CsLPEAT2b was treated as reference (Figures 7 and 8). 

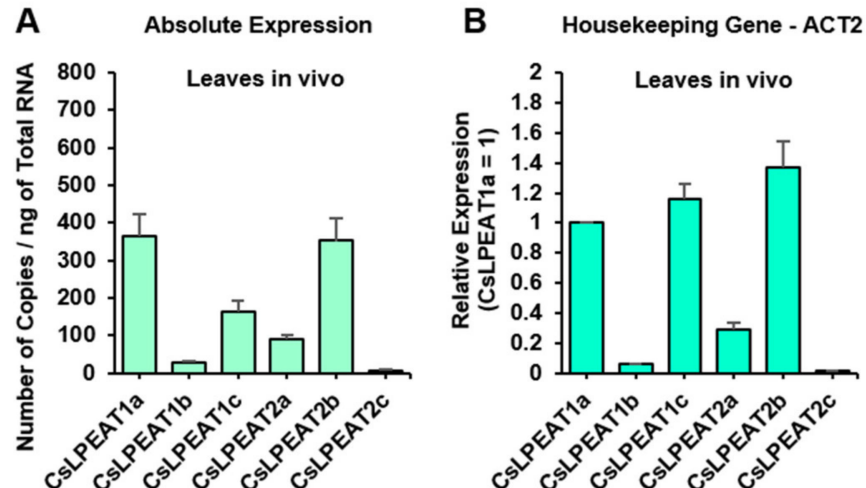

C Housekeeping Gene - TIP41

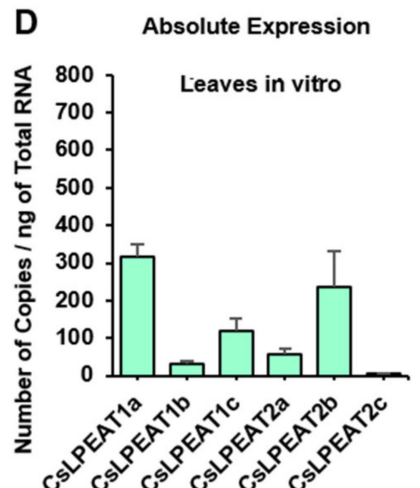

E
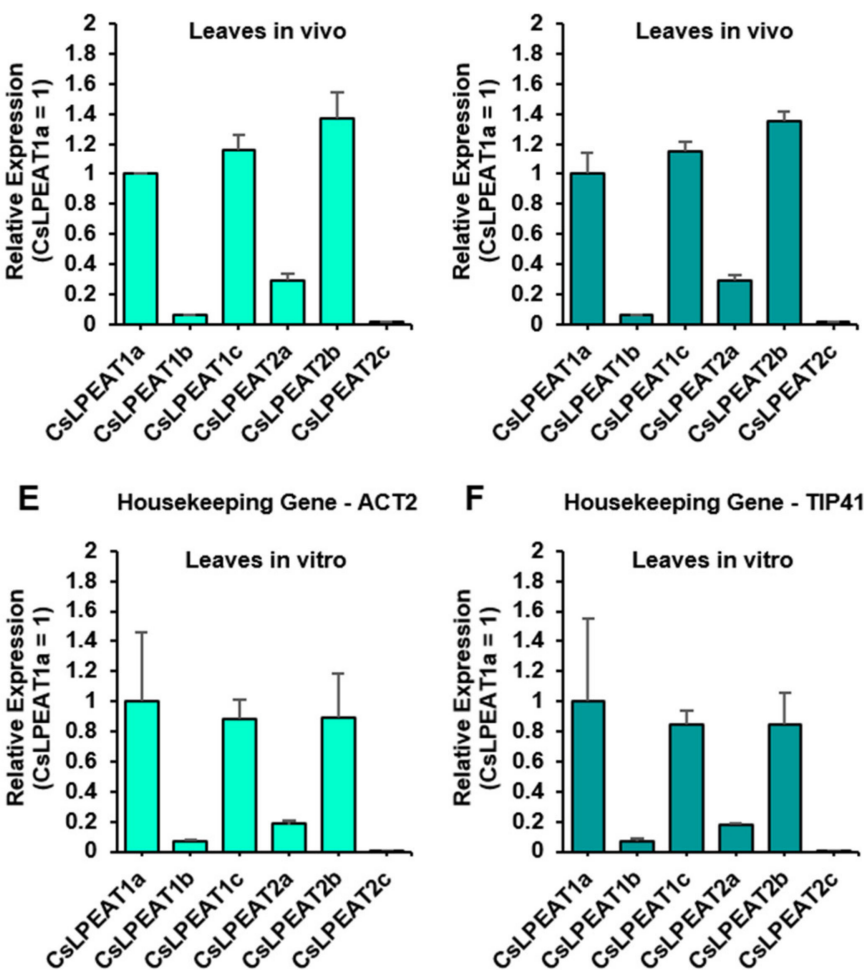

F Housekeeping Gene - TIP41

G Absolute Expression

H

Housekeeping Gene - ACT2
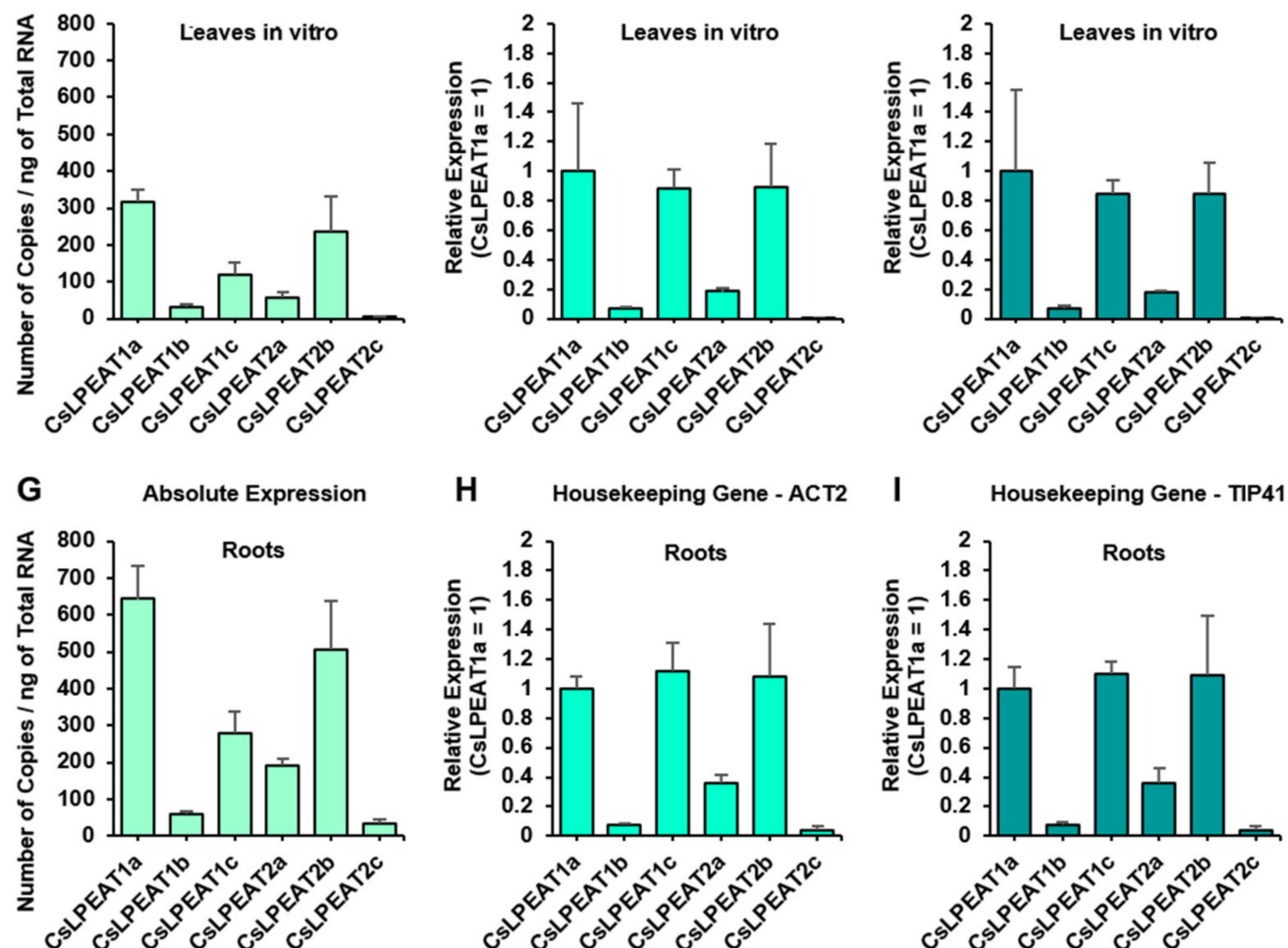

I Housekeeping Gene - TIP41

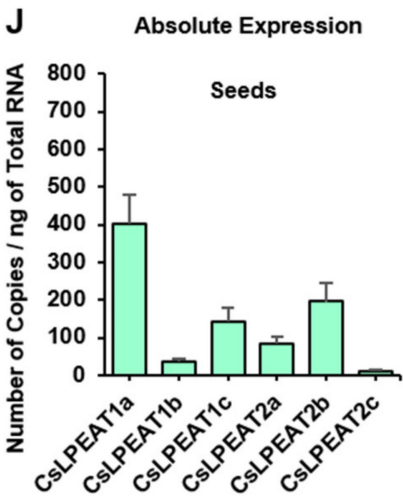

K Housekeeping Gene - ACT2
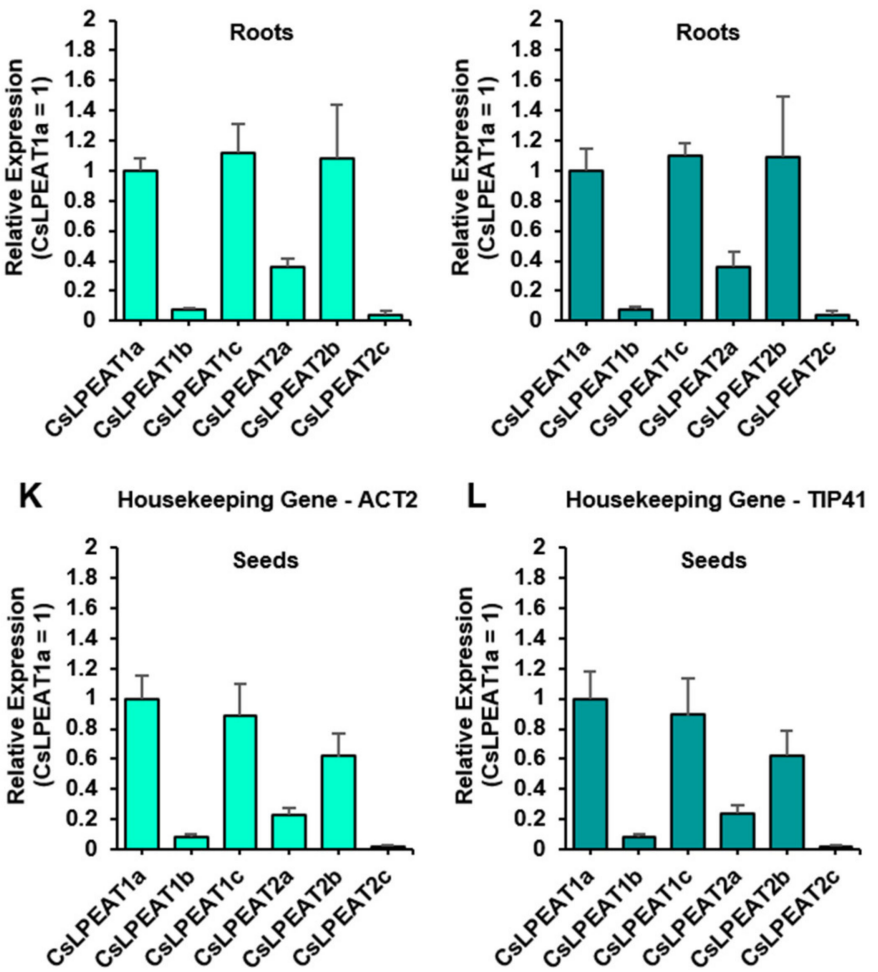

Figure 5. Analysis of differences in CsLPEAT1 and CsLPEAT2 isoform expression between different plant tissues: in vivo leaves $(\mathbf{A}-\mathbf{C})$, in vitro leaves $(\mathbf{D}-\mathbf{F})$, in vitro roots $(\mathbf{G}-\mathbf{I})$ and seeds $(\mathbf{J}-\mathbf{L})$. Panels $(\mathbf{A}, \mathbf{D}, \mathbf{G}, \mathbf{J})$ represent absolute quantification expression measurements, while other panels represent relative expression in comparison to CsACT2 (B,E,H,K) and CsTIP41 $(\mathbf{C}, \mathbf{F}, \mathbf{I}, \mathbf{L})$. Error bars indicate standard deviations (SD) between biological replicates $(n=3)$. 


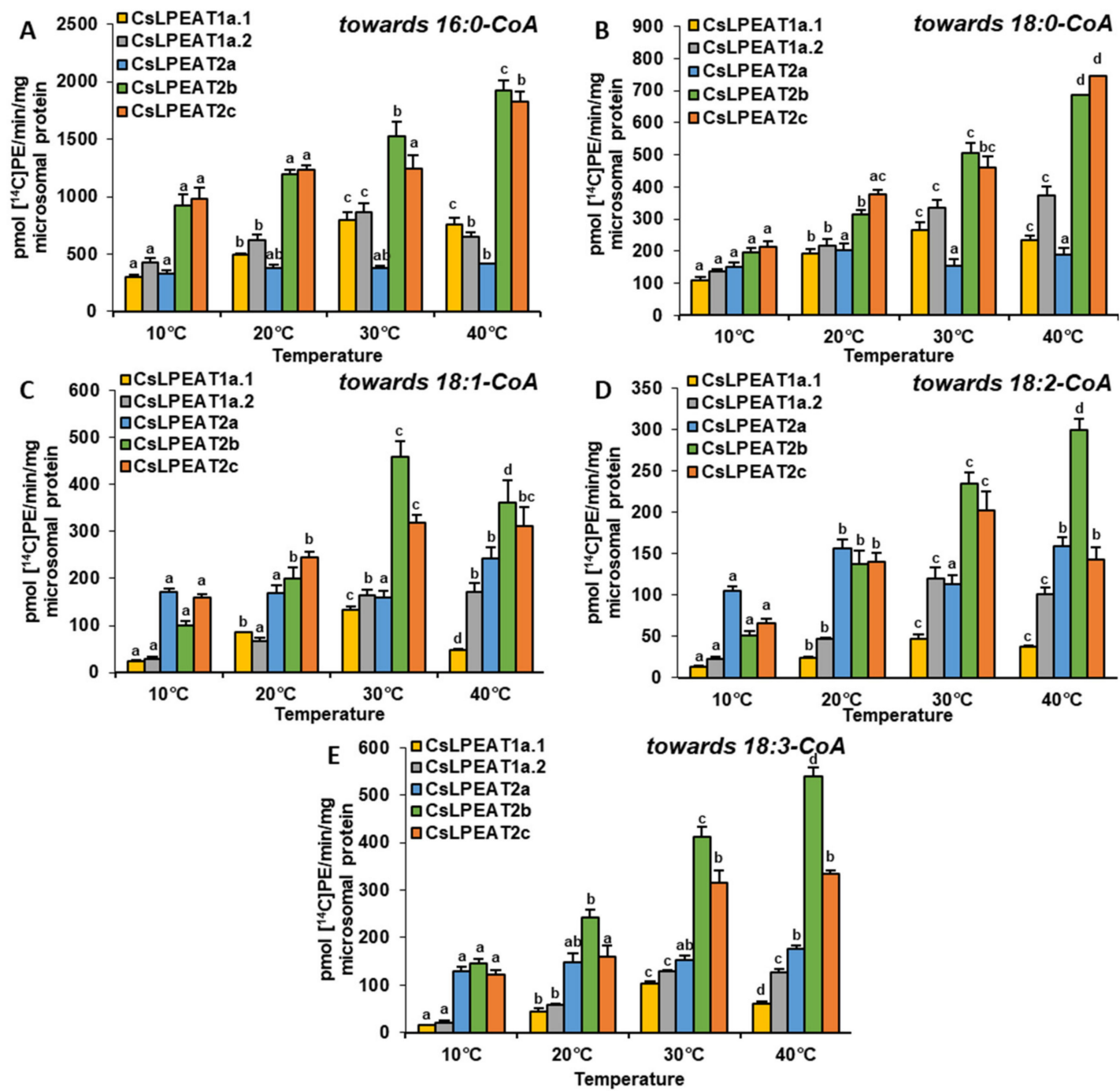

Figure 6. Acyl-CoA specificities of CsLPEAT isoforms with various acyl-CoA donors and 18:1-LPE as an acyl acceptor, in a yeast system. Each panel corresponds to activity towards a different acyl donor: (A) —16:0-CoA, (B) - 18:0-CoA, (C) —-18:1CoA, (D) - 18:2-CoA and (E)-18:3-CoA. Error bars indicate the SD between at least three repeats $(n \geq 3)$. Statistical analysis of the difference in activity of each isoform at various tested temperatures were done by one-way ANOVA followed by Tukeys test. Different letters indicate significant difference $(p \leq 0.05)$. 


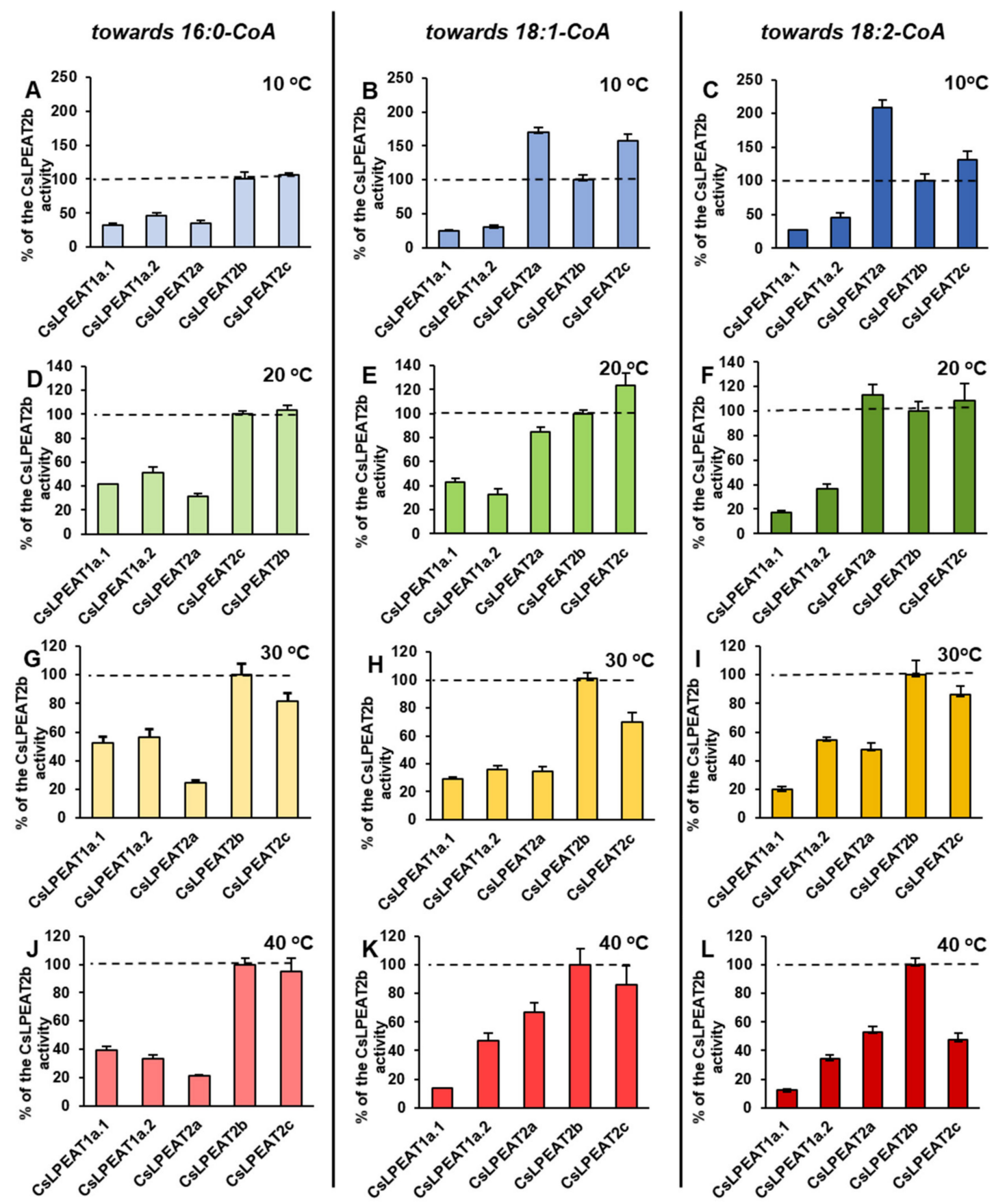

Figure 7. Preferences towards different acyl donors of CsLPEAT isoforms at different temperatures. Activities of CsLPEAT isoforms are presented in corresponding panel: towards 16:0-CoA (A,D,G,J), towards 18:1-CoA (B,E,H,K), towards 18:2-CoA $(\mathbf{C}, \mathbf{F}, \mathbf{I}, \mathbf{L})$. Activities are expressed as percentages of CsLPEAT2b activity with a particular acyl-CoA. The data presented in Figure 6 were used for the calculations. Error bars indicate the SD between at least three repeats $(n \geq 3)$. 

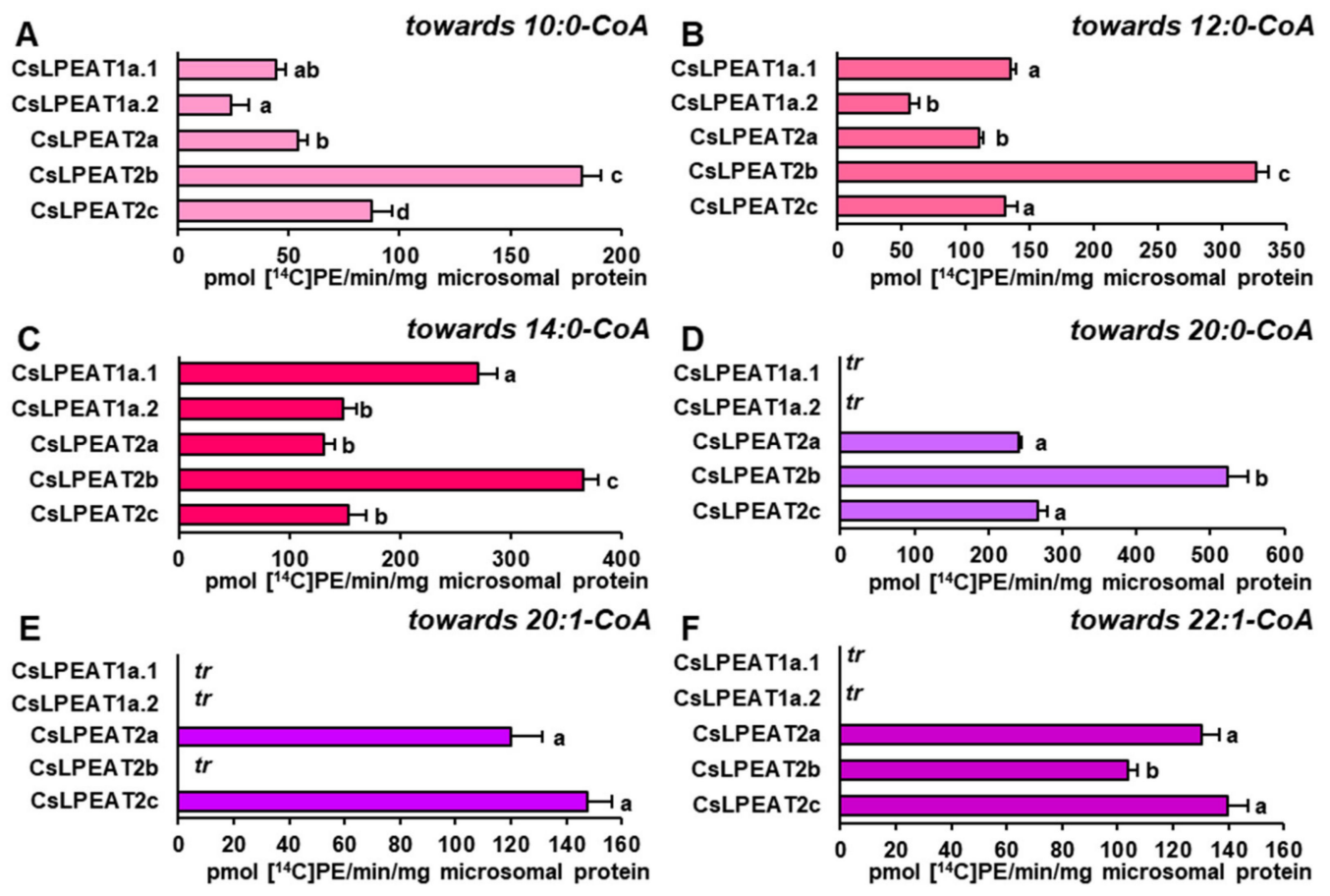

Figure 8. Acyl-CoA specificity of CsLPEAT isoforms towards short and very long chain acyl-CoA donors and 18:1-LPE as an acyl acceptor, in yeast system. Panel (A-C) correspond to medium-chain fatty acids (10:0-CoA, 12:0-CoA and 14:0-CoA, respectively), and panel (D-F) toward VLCFA (20:0-CoA, 20:1-CoA and 22:1-CoA, respectively). Error bars indicate the SD between at least three repeats $(n \geq 3)$. Statistical analysis of the difference in activity of each isoform at various tested temperatures were done by one-way ANOVA followed by Tukey's test. Different letters indicate significant difference $(p \leq 0.05)$.

The obtained results showed that 16:0-CoA was the most favored, by all CsLPEAT enzymes, fatty acid donor at each tested temperature. Variants of CSLPEAT1 enzymes reached the highest activity towards this acyl group at $30{ }^{\circ} \mathrm{C}$. CSLPEAT1a activity increased about 2.7 times (up to $798 \mathrm{pmol}$ of de novo synthesized PE $/ \mathrm{min} / \mathrm{mg}$ microsomal protein), whereas CsLPEAT1b increased about 2.0 times (up to 861 pmol of de novo synthesized $\mathrm{PE} / \mathrm{min} / \mathrm{mg}$ microsomal protein) compared to the lowest activity, detected at $10{ }^{\circ} \mathrm{C}$. A further temperature increase from 30 to $40{ }^{\circ} \mathrm{C}$ reduced the activity by 6 and $25 \%$ for CsLPEAT1a.1 and CsLPEAT1a.2, respectively. CsLPEAT1 enzymes were not the most active in comparison to the other tested CsLPEAT enzymes. They obtained approximately $52-56 \%$ of maximum CsLPEAT2b activity at $30^{\circ} \mathrm{C}$. The CsLPEAT2b and CsLPEAT2c peaks of activity were detected at $40{ }^{\circ} \mathrm{C}$. They doubled their lowest activity at $10^{\circ} \mathrm{C}$ and reached the activity of approximately $1900 \mathrm{pmol}$ of de novo synthesized $\mathrm{PE} / \mathrm{min} / \mathrm{mg}$ microsomal protein, which makes them the most active among all tested CsLPEAT enzymes. The CsLPEAT2a variant exhibited a rather stable preference, regardless of temperature changes; their activity increased only slightly between $10^{\circ} \mathrm{C}$ and $40^{\circ} \mathrm{C}$. This variant also revealed the lowest activity towards 16:0-CoA among all tested CsLPEATs; at $10^{\circ} \mathrm{C}$ it reached $35 \%$ and parallel with increasing temperature its activity declined to $21 \%$ of CsLPEAT2b activity (Figures 6A and 7A,D,G,J).

The second tested acyl group, 18:0-CoA, was primarily favored by CsLPEAT2c enzyme, regardless of temperature (except for $30^{\circ} \mathrm{C}$, at which temperature 18:0-CoA was a bit better accepted by the CsLPEAT2b isoform). The CsLPEAT2c activity with 18:0-CoA gradually raised with temperature up to $40^{\circ} \mathrm{C}$, reaching activity equal to $745 \mathrm{pmol}$ of de novo synthesized PE $/ \mathrm{min} / \mathrm{mg}$ microsomal protein, 3.5 times greater than at $10^{\circ} \mathrm{C}$. CsLPEAT $2 \mathrm{~b}$ and CsLPEAT1a.2 also elevated their activity towards 18:0-CoA parallel with increasing temperature, attaining $346 \%$ and $275 \%$ of the activity detected at minimal temperature. The activity of CsLPEAT1a.1 was amplified 2.5 times between $10{ }^{\circ} \mathrm{C}$ and $30^{\circ} \mathrm{C}$. Further 
increase in temperature only marginally decreased CsLPEAT1a.1 activity. Similarly, to its activity towards 16:0-CoA, CsLPEAT2a did not exhibit any significant changes in preference towards 18:0-CoA due to temperature changes. Its activity fluctuated between 151 and $204 \mathrm{pmol}$ of de novo synthesized PE/min/mg microsomal protein (Figure 6B).

The activity of analyzed enzymes towards 18:1-CoA was distinguished by the greatest variability. At $10{ }^{\circ} \mathrm{C}, 18: 1-\mathrm{CoA}$ was very efficiently utilized by CsLPEAT2a and CsLPEAT2c, what amounted to 171 and $158 \mathrm{pmol}$ of de novo synthesized PE/min/mg microsomal protein. These isoforms have been $70 \%$ and $58 \%$ more active than the CsLPEAT2b reference. CSLPEAT2a maintained a rather stable activity for most temperatures, a maximum value obtained at $40{ }^{\circ} \mathrm{C}$, which was equal to $242 \mathrm{pmol}$ of de novo synthesized $\mathrm{PE} / \mathrm{min} / \mathrm{mg} \mathrm{mi}-$ crosomal protein. Regarding CsLPEAT2c enzyme, its activity at $20^{\circ} \mathrm{C}$ dominated over the rest of the tested isoforms. Compared to relative activity of the chosen reference its activity was $24 \%$ higher and constituted about $246 \mathrm{pmol}$ of de novo synthesized $\mathrm{PE} / \mathrm{min} / \mathrm{mg} \mathrm{mi}-$ crosomal protein. The increased temperature favored the action of CsLPEAT2b, especially at $30{ }^{\circ} \mathrm{C}$ when $\mathrm{CsLPEAT} 2 \mathrm{~b}$ activity reached $460 \mathrm{pmol}$ of de novo synthesized $\mathrm{PE} / \mathrm{min} / \mathrm{mg}$ microsomal protein-which was CsLPEAT2b maximum activity. At $40{ }^{\circ} \mathrm{C}$ the isoform's activity declined by $22 \%$, however, it remained the most active variant towards 18:1-CoA. The participation in utilization of 18:1-CoA by CsLPEAT1 enzymes was rather modest. CsLPEAT1a.1 was most active at $30{ }^{\circ} \mathrm{C}$. Further increase of temperature dramatically decreased utilization of this acyl donor by $65 \%$ compared to the maximum. In case of CsLPEAT1a.2, its activity was higher at higher temperatures and attained the peak of its activity at $40{ }^{\circ} \mathrm{C}$. The relative activity compared to the reference variant was the highest at $20{ }^{\circ} \mathrm{C}$ (43\% of reference activity) and at $40{ }^{\circ} \mathrm{C}$ (47\% of reference activity) for CsLPEAT1a.1 and CsLPEAT1a.2, respectively (Figures $6 \mathrm{C}$ and $7 \mathrm{~B}, \mathrm{E}, \mathrm{H}, \mathrm{K}$ ).

Similar, to the above described utilization of 18:1-CoA, the utilization of 18:2-CoA also varied depending on the temperature and enzymes. Nevertheless, this acyl donor was the least accepted one. At 10 and $20^{\circ} \mathrm{C}$, CsLPEAT2a was more active than other tested enzymes with 18:2-CoA. Its activity attained 104 and $150 \mathrm{pmol}$ of de novo synthesized $\mathrm{PE} / \mathrm{min} / \mathrm{mg}$ microsomal protein, and showed $107 \%$ and $13 \%$ greater activity than reference, respectively, at those temperatures. At higher temperatures, CsLPEAT2a activity with 18:2CoA fluctuated between 112 and $158 \mathrm{pmol}$ of de novo synthesized PE/min $/ \mathrm{mg}$ microsomal protein, finally obtaining about $50 \%$ of reference activity. The second variant most active with 18:2-CoA at the range of $10-30{ }^{\circ} \mathrm{C}$ was CsLPEAT2c. Its activity progressively increased from 66 to $202 \mathrm{pmol}$ of de novo synthesized PE/min/mg microsomal protein. CsLPEAT2c activity towards 18:2-CoA started (in this range of temperatures) from activity $31 \%$ higher and ending with activity $15 \%$ lower than reference. At $40{ }^{\circ} \mathrm{C}$ relative activity of CsLPEAT2c with 18:2-CoA decreased to about $50 \%$ of the reference one. The CsLPEAT1 enzymes again exhibited the lowest activity towards 18:2-CoA. Both reached peak activity at $30^{\circ} \mathrm{C}: 47$ and $119 \mathrm{pmol}$ of de novo synthesized $\mathrm{PE} / \mathrm{min} / \mathrm{mg}$ microsomal protein for CsLPEAT1a and CsLPEAT1b, respectively. Their relative activity was the highest at $30{ }^{\circ} \mathrm{C}$ reaching approximately 10 and 55\% of reference activity with 18:2-CoA, respectively for CsLPEAT1a and CsLPEAT1b (Figures 6D and 7C,F,I,L).

The activity of all tested enzymes towards 18:3-CoA revealed strong efficiency of utilization of this acyl donor by CsLPEAT2 enzymes. Parallel with rising temperature activity of CsLPEAT2a and CsLPEAT2b increased 2.7 and 3.7 times, respectively. CsLPEAT2a activity, similar to other acyl groups, did not differ significantly regardless of temperature. It maintained efficiently utilizing 18:3-CoA at similar levels, which oscillated between 128 and $175 \mathrm{pmol}$ of de novo synthesized PE/min/mg microsomal protein. The activity of CsLPEAT1 enzymes towards 18:3-CoA was rather negligible at $10{ }^{\circ} \mathrm{C}$. At higher temperatures CsLPEAT1a.1 efficiency with 18:3-CoA slowly enhanced, reaching maximum at $30{ }^{\circ} \mathrm{C}$ and then being reduced by $40 \%$ at $40{ }^{\circ} \mathrm{C}$. CsLPEAT1a.2 activity with 18:3-CoA also increased and reached a constant at 30 and $40^{\circ} \mathrm{C}-125 \mathrm{pmol}$ of de novo synthesized $\mathrm{PE} / \mathrm{min} / \mathrm{mg}$ microsomal protein (Figure 6E). 


\subsection{CSLPEAT2 Isoforms Are Specific towards Saturated and Very-Long-Chain Fatty Acids}

Considering the possible availability of short and very-long-chain fatty acids in acylCoA pool and to determine fringe specificities of each CsLPEATs, their preferences towards these acyl groups were examined. Reactions were conducted at $30^{\circ} \mathrm{C}$ and 18:1-LPE was chosen as an acyl acceptor (Figure 8).

Short, saturated acyl-CoA were utilized by all enzymes. The highest specificity was detected towards 14:0-CoA, especially by CsLPEAT2b and CsLPEAT1a.1 enzymes, which activity amounted to 365 and $270 \mathrm{pmol}$ of de novo synthesized PE $/ \mathrm{min} / \mathrm{mg}$ microsomal protein. The other tested enzymes utilized 14:0-CoA with similar efficiency, which amounted to approximately 132-150 pmol of de novo synthesized PE $/ \mathrm{min} / \mathrm{mg}$ microsomal protein (Figure 8C). All tested enzymes were also active with 12:0-CoA and 10:0-CoA with similar preference pattern towards both. The lowest activity was detected for CsLPEAT1a.2, whereas CsLPEAT2b was the most active isoform with those acyl-CoA. CsLPEAT1a.2 activity with 12:0-CoA amounted to $56 \mathrm{pmol}$ of de novo synthesized PE $/ \mathrm{min} / \mathrm{mg}$ microsomal protein and CsLPEAT2b activity with 12:0-CoA amounted to 328 pmol of de novo synthesized $\mathrm{PE} / \mathrm{min} / \mathrm{mg}$ microsomal protein. Both activities were twice higher than the corresponding activities with 10:0-CoA. The activity of other enzymes declined in similar manner with 10:0-CoA. Only CsLPEAT1a.1 activity with 10:0-CoA (the second most active variant with 12:0-CoA) was reduced not two but three times (Figure $8 \mathrm{~A}-\mathrm{C}$ ).

On the other hand, acyl donors with very-long-chain fatty acids were accepted only by CsLPEAT2 enzymes. The highest preference was detected towards 20:0-CoA. Additionally, for CsLPEAT2a and CsLPEAT2b, it was the second most favored acyl donor. Their activity with this acyl-CoA amounted to 523 and $241 \mathrm{pmol}$ of de novo synthesized PE $/ \mathrm{min} / \mathrm{mg}$ microsomal protein, which constituted $65 \%$ and $35 \%$ of their activity towards $16: 0-\mathrm{CoA}$, respectively. CsLPEAT2c activity was similar to its specificity towards $18 \mathrm{C}$ unsaturated fatty acids and amounted to about $266 \mathrm{pmol}$ of de novo synthesized PE $/ \mathrm{min} / \mathrm{mg}$ microsomal protein, being the second most active variant towards 20:0-CoA (Figure 8D). Two other very-long-chain acyl donors were utilized with similar efficiency (Figure 9E,F). CsLPEAT2c enzymes revealed a little bit higher activity towards 20:1-CoA and 22:1-CoA, reaching 148 and $140 \mathrm{pmol}$ of de novo synthesized $\mathrm{PE} / \mathrm{min} / \mathrm{mg}$ microsomal protein, respectively. CsLPEAT2a enzymes activity was reduced by $20 \%$ and $8 \%$ compared to CsLPEAT2c activity towards 20:1-CoA and 22:1-CoA, respectively. CsLPEAT2b utilized 22:1-CoA to a lesser extent than the two other CsLPEAT2 isoforms, reaching activity equal to $104 \mathrm{pmol} / \mathrm{min} / \mathrm{mg}$ microsomal protein. CsLPEAT2b specificity towards 20:1-CoA was poor and only trace levels of de novo synthesized PE could be detected (Figure 8D-F).

\subsection{Distinct Ability or Inability to Utilize Various Acyl Acceptors by CsLPEAT Enzymes}

Based on previous tests describing fatty acids composition of $s n-1$ position of PE of $C$. sativa leaves, assays determining CsLPEAT activity and substrate specificity with different acyl acceptors such as 16:0-LPE and 18:2-LPE were conducted. Again, five most abundant fatty acids present in PE pool of different tissues were chosen. Assays with 18:1-LPE were described in previous section. 
A

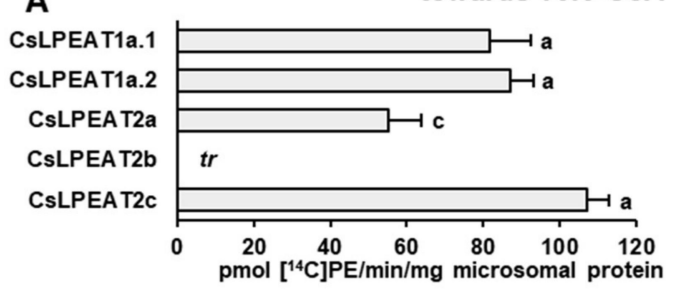

C

CsLPEAT1a.1

CsLPEAT1a.2

CsLPEAT2a

CsLPEAT2b

CsLPEAT2C

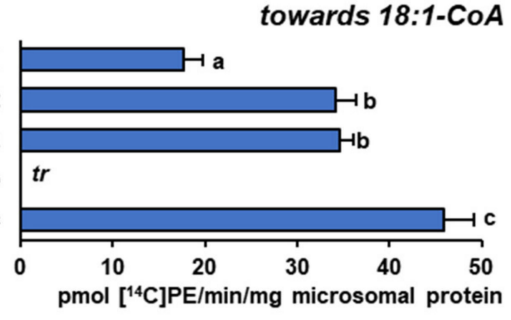

E

\section{B}

CsLPEAT1a.1

CsLPEAT1a.2

CsLPEAT2a

CsLPEAT2b

CsLPEAT2c
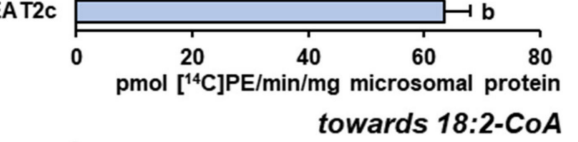

CsLPEAT1a.1

CsLPEAT1a.2

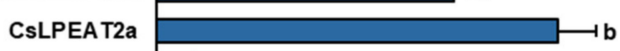

CsLPEAT2b

CsLPEAT2c

tr

0.60

$\begin{array}{lccr}0 & 20 & 40 & 60\end{array}$

towards 18:3-CoA

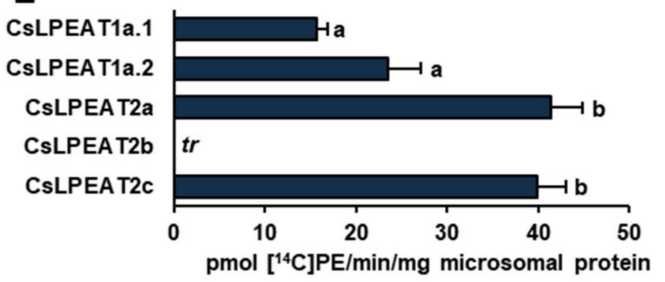

Figure 9. Acyl-CoA specificities of CsLPEAT isoforms with various acyl-CoA donors and 16:0-LPE as an acyl acceptor, in a yeast system: (A)—towards 16:0-CoA, (B)—towards 18:0-CoA, (C)—towards 18:1-CoA, (D)—towards 18:2-CoA and (E) - towards 18:3-CoA. Error bars indicate the SD between at least three repeats $(n \geq 3)$. Statistical analysis of the difference in activity of each isoforms at various tested temperature were done by one-way ANOVA followed by Tukeys test. Different letters indicate significant difference $(p \leq 0.05)$.

Despite the predominant presence of $16: 0$ at $s n-1$ position, the activity of CsLPEAT enzymes towards 16:0-LPE was much smaller compared to other tested LPE. CsLPEAT2b even exhibited no activity (on the detection level) towards this acyl acceptor. The tested enzymes preferred 16:0-CoA as an acyl donor, especially CsLPEAT2c, followed by CsLPEAT1a.2 and 1a.1, and by CSLPEAT2a: 107, 87, 82 and $55 \mathrm{pmol}$ of de novo synthesized PE/min $/ \mathrm{mg}$ protein, respectively (Figure 9A). The 18:0-CoA and 18:1-CoA were utilized in a comparable manner. CsLPEAT2c exhibited the highest preference, and its activity amounted to approximately 63 and $45 \mathrm{pmol}$ of de novo synthesized $\mathrm{PE} / \mathrm{min} / \mathrm{mg}$ protein, respectively. The CsLPEAT1a.2 and CsLPEAT2a showed the same activity towards both acyl donors in the range of 34-36 pmol of de novo synthesized $\mathrm{PE} / \mathrm{min} / \mathrm{mg}$ protein. The second to last active variant was CsLPEAT1a.1. Its activity towards both acyl-donors reached only $40 \%$ of maximum activity exhibited by CsLPEAT2c (Figure 9B,C). Towards 16:0-LPE and 18:2-CoA only CsLPEAT2a, CsLPEAT1a.2 and CsLPEAT1a.1 were functional, in this order, reaching 51,38 and $29 \mathrm{pmol}$ of de novo synthesized $\mathrm{PE} / \mathrm{min} / \mathrm{mg}$ protein of activity (Figure 9D). Towards 18:3-CoA, the highest preference was shown by CsLPEAT2a. Other enzymes (except non-active CsLPEAT2b) reached 97 (CsLPEAT2c), 57 (CsLPEAT1a.2) and $38 \%$ (CsLPEAT1a.1) of its activity (Figure 9E). The third tested acyl acceptor was 18:2-LPE. Linolenic acid is the third most abundant fatty acid present in $s n-1$ position of PE in leaves, it constitutes approximately $13 \%$ of all the fatty acids at that stereospecific position. In assays with this acyl acceptor, 16:0-CoA was most efficiently utilized by all CsLPEAT2 enzymes reaching 1718, 1475 and $856 \mathrm{pmol}$ of de novo synthesized $\mathrm{PE} / \mathrm{min} / \mathrm{mg}$ protein for isoforms 2c, 2b, and 2a, respectively. CsLPEAT1a variants utilized this acyl donor on significantly lower level, only 8 and $11 \%$ of maximum activity towards this fatty acid for CsLPEAT1a.1 and CsLPEAT1a.2, respectively (Figure 10A). Both 1a.1 and 1a.2 variants exhibited the highest preference towards 18:0-CoA, which accounted for respectively about 19 and $30 \%$ of maximum activity towards 18:0-CoA. Again, CsLPEAT2c was the most active 
enzyme, followed by $2 \mathrm{~b}$ and $2 \mathrm{a}$ isoforms reaching in order 1162,899 and 460 pmol of de novo synthesized PE/min/mg protein (Figure 10B). Variants of CsLPEAT1a exhibited quite similar activity towards unsaturated fatty acids donors: towards 18:1-CoA 106-142, towards 18:2-CoA 69-76 and towards 18:3-CoA 89-91 $\mathrm{pmol}$ of de novo synthesized PE/min/mg protein. Among the CsLPEAT2 isoforms 18:1-CoA was best utilized in assays with 18:2-LPE by isoform 2 c, followed by $2 \mathrm{~b}$ and then $2 \mathrm{a}$. Those activities amounted to 887,511 and $430 \mathrm{pmol}$ of de novo synthesized $\mathrm{PE} / \mathrm{min} / \mathrm{mg}$ protein, respectively. Similar values were observed towards 18:3-CoA: 874, 640 and $430 \mathrm{pmol} \mathrm{PE} / \mathrm{min} / \mathrm{mg}$ protein, respectively. A different manner of preference was observed towards 18:2-CoA, where the best utilization efficiency was shown by CsLPEAT2b, followed by CsLPEAT2c and then by CsLPEAT2a. CsLPEAT2b activity in assays with 18:2-LPE and 18:2-CoA accounted for 553 pmol of de novo synthesized $\mathrm{PE} / \mathrm{min} / \mathrm{mg}$ protein, whereas two other enzymes exhibited $94 \%$ (CsLPEAT2c) and 52\% (CsLPEAT2a) of that activity (Figure 10C-E).

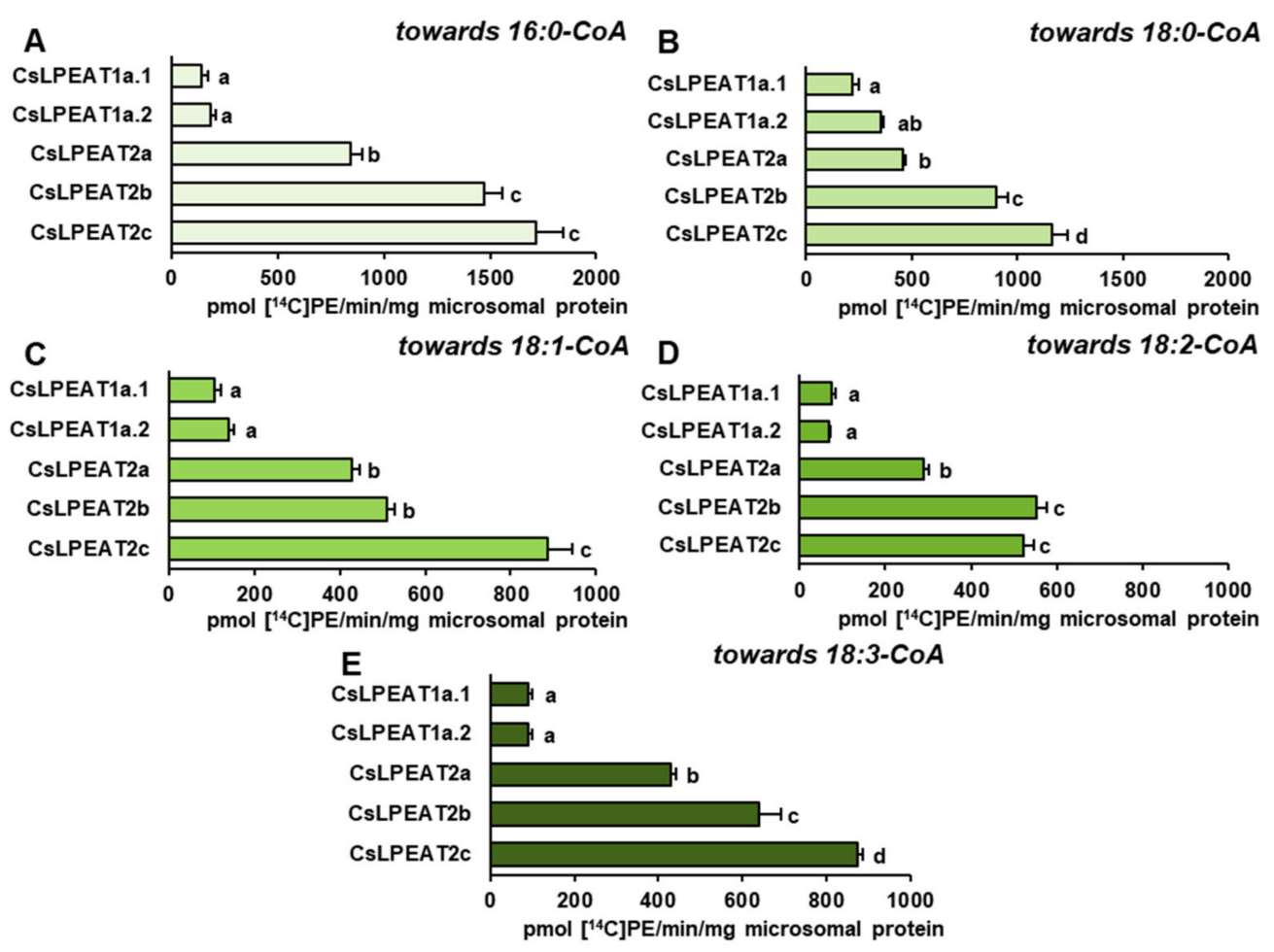

Figure 10. Acyl-CoA specificities of CsLPEAT isoforms with various acyl-CoA donors and 18:2-LPE as an acyl acceptor, in a yeast system: (A)—towards 16:0-CoA, (B)—towards 18:0-CoA, (C)—towards 18:1-CoA, (D)—towards 18:2-CoA and (E) - towards 18:3-CoA. Error bars indicate the SD between at least three repeats $(n \geq 3)$. Statistical analysis of the difference in activity of each isoform at various tested temperatures were done by one-way ANOVA followed by Tukeys test. Different letters indicate significant difference $(p \leq 0.05)$.

\section{Discussion}

3.1. Acyl-CoA: Lysophosphatidyethnolamine Acytransferases Present in Vegetative and Generative Organs of C. sativa Respond Directly to Temperature Changes and Shape Phospholipids' Composition

In our experiments, chill temperature promoted LPEAT enzymes substrate specificity towards 18:3-CoA. The reverse affinity was observed at higher temperatures, greater than $30^{\circ} \mathrm{C}$, where declining specificity towards $18: 3-\mathrm{CoA}$ and raising specificity towards monounsaturated 18:1-CoA were noticed. These preferences correlate with the fatty acid composition of acyl-lipids present in plants subjected to altered temperatures. A previous study on oily plants, grown in higher temperatures, revealed that seeds of such plants produced decreased levels of 18:2 and 18:3, and increased of 18:1 content [31-33]. Studies 
conducted on $A$. thaliana showed that leaf membrane lipid composition was characterized by a decrease in levels of 18:3 and 16:3, and elevated levels of 16:0 and 18:1. Leaf tissue exposed to heat stress also possessed higher amounts of 18:2, in contrast to the seeds [34-37]. In our study, similar preference towards 18:2-CoA was observed in case of LPEAT enzymes present in vegetative organs. It was similarly not observed in seed tissue. The C. sativa in vivo leaves were the only studied tissue with strong preference towards 16:0-CoA at high temperature. This preference may be an adaptation to heat stress to maintain proper, solid membrane structure in tissues most exposed to environmental conditions [35]).

Previously observed changes also concerned the PE pool, in which the amount and composition of fatty acids adjusted to the temperature. The studies, conducted at temperatures below $5{ }^{\circ} \mathrm{C}$, revealed that levels of PE in Brassica napus and in A. thaliana leaves were elevated and characterized by lipid molecular species possessing linoleic acid [34,38]. On the contrary, heat-stressed plants exhibited significantly reduced levels of PE and reduced amounts of 18:3. Furthermore, amounts of oleic acid increased in all molecular species [37]. The possible changes of PE composition are consistent with LPEATs preferences, which may play a dominant role in their regulation, especially its affinity towards 18:1-CoA and 18:3-CoA at various temperatures. It has been previously proven that trienoic fatty acids boosted plant tolerance in colder temperatures, while its diminishing amount at higher temperatures influenced better acclimatization [39].

Phosphatidylethanolamine is one of the most abundant phospholipids in plant tissues. The observed correlation of LPEAT activity with different tissues acyl composition and PE pool may arise not only from its physiological role in vegetative tissues. PE was also shown as a major substrate for PDAT enzyme in vitro activity (TAG production). If $\mathrm{PE}$ is a substrate for PDAT in vivo its acyl profile may influence the final oilseed plants seed composition [17]. The observed, higher amounts of 18:3 in PE pool after cold stress correlated with elevated expression of PDAT1-A, present in C. sativa seeds, cultivated at low temperature. PDAT1 possesses a high preference towards this fatty acid [40].

The highest activity towards each of the tested acyl donors was observed at $30{ }^{\circ} \mathrm{C}$. The same temperature optimum was also noticed for other LPLAT enzymes present in C. sativa [26,28]. Declined activity was mainly observed at $10{ }^{\circ} \mathrm{C}$ and $40{ }^{\circ} \mathrm{C}$. In those thermal conditions, the detrimental effects of temperature on protein may appear, leading in cold to inhibition of enzymatic activity, and in heat to inactivation of protein by gradual denaturation [1].

The observed distinction in acyl donor preference, in some way was also proven by competence assays conducted for microsomal fractions derived from leaves, which exhibited the most fluctuating preferences and activities due to temperatures in our study. Assays were conducted with addition of BSA, which mimiCs the activity of ACBP present in vivo. In in vitro conditions BSA, similarly to ACBP in vivo, can bind acyl-CoAs and reduce availability of free acyl-CoAs for the acyltransferases, imitating natural conditions [41,42]. In both temperatures $\left(10\right.$ and $\left.30{ }^{\circ} \mathrm{C}\right), 18: 1-\mathrm{CoA}$ was better utilized than 18:3-CoA, however the biggest dissimilarities were observed at $30^{\circ} \mathrm{C}$, where 18:3-CoA was accepted at least 3 times worse than 18:1-CoA. At elevated temperatures, LPEATs present in vitro leaves also exhibited higher relative preference towards 16:0-CoA, which was not previously noticed in substrate specificity tests. In such assays, however, the elevated absolute activity for 16:0-CoA increased up to $30^{\circ} \mathrm{C}$. Observed preferences, which are not fully correlated with observed preferences towards single acyl donors, demonstrate that in acylation of LPE in in vivo conditions, substrate specificities of LPEAT enzymes are not the only factor, which matters. The availability of individual acyl-CoA in cytosolic acyl-CoA pool also plays an important role. The main source of acyl-CoA in this pool are plastids where fatty acids are synthesized. Plastids enrich cytosolic pool of acyl-CoA mainly with 18:1-CoA and in smaller amounts with 16:0-CoA and 18:0-CoA. The composition of cytosolic acyl-CoA pool can be regulated also by reverse reaction of LPLAT enzymes, especially by LPCAT, which supplements this pool in unsaturated fatty acids by transferring modified fatty acids from PC, major place of desaturase activity [28,43] (Li-Beisson et al. 2013, Klińska et al. 
2019). Based on Ruiz-Lopez et al.'s [44] study, the dominant 18C acyl-CoA in cytosolic acyl-CoA pool is 18:1-CoA, towards which, in our competence assay, microsomal LPEAT enzymes exhibited the highest preference. It was also the best utilized acyl donor in assays determining the intensity of PE remodeling. These assays were conducted for leaves in vivo microsomal fractions, at two different temperatures to estimate how efficient the remodeling process is in tissues most exposed to ambient temperatures. We estimated the potential time of complete fatty acid turnover in PE pool. Calculations were made for remodeling of the $s n-1$ and $s n-2$ positions simultaneously, but we must remember that fatty acids from $s n-2$ position are most preferred in acyl editing process and complete exchange of this position can be shorter. The observed remodeling intensity was highly dependent on temperature. At $30{ }^{\circ} \mathrm{C}$ its intensity was about 3 to about 5 times faster (depending on acyl-CoA added to the assays) than at $10^{\circ} \mathrm{C}$. The dependence of remodeling intensity on a kind of acyl-CoA present in the assay was a bit surprising as the participation of backward LPEAT reaction in this process was rather small (data not presented). Thus, this data suggests, that the kind of acyl-CoA present in the assays effects the formation of LPE, e.g., via lipase or PDAT activity and in this way affects remodeling intensity. However, so far there is no information about this type of effects caused by acyl-CoA and this issue needs further study. Of the tested acyl-CoA 18:1-CoA had the highest effect on such a reaction and 18:3-CoA had the lowest effect. However, at $30^{\circ} \mathrm{C} 18: 2-\mathrm{CoA}$ was even more effective than 18:1-CoA.

The physiological importance of the observed acyl-CoA effect on lysophospholipid formation is hard to explain in regards to PE. It is possible that it is a common phenomenon, similar for all phospholipids. In our previous study, we have observed similar feature of the PC [28]. In in vitro tests utilizing C. sativa microsomal fractions, the rate of PC remodeling was the highest, when the reaction mixture included 18:1-CoA, lower when it included 18:2-CoA, and slowest with 18:3-CoA. Plastid-derived 18:1 must be desaturated on PC to produce 18:2 and 18:3. Thus, the stimulating effect of 18:1-CoA on LPC production could have an important physiological significance. Equivalent physiological importance of higher 18:1-CoA incorporation into PE needs further investigation.

The tested LPEATs are enzymes involved in the synthesis of $\left[{ }^{14} \mathrm{C}\right] \mathrm{PE}$ from LPE and $\left[{ }^{14} \mathrm{C}\right]$ acyl-CoA. However, PE and LPE (via reverse reaction) can also be synthesized by other LPLATs [20]. Consequently, we cannot measure the exact activity of LPEATs in our assays with microsomal fractions derived from plant tissues. Nevertheless, based on previously demonstrated substrate specificity $[26,28]$ as well as based on the presented temperature-dependent substrate specificity, we can certainly assume that LPEAT enzymes play the leading role in PE production via LPLAT action. The role in temperature sensing for LPCAT enzymes, which can also acylate LPE, was rather poor; temperature alterations did not influence any substrate preferences of LPCAT enzymes present in leaves and roots.

\subsection{The Origin of the CSLPEAT Isoforms, and Their Diverse Expression Pattern in C. sativa Organs}

C. sativa is a hexaploid organism, which originated from two genome hybridization events. First hybridization event occurred between members of two organisms, both possessing a Camelina neglecta-like genome, leading to generation of an auto-allotertaploid $(4 n)$. The second hybridization happened interspecies between the auto-allotetraploid and Camelina hispida. As a result, C. sativa is comprised of three stable subgenomes [29]. On account of the high complexity of Camelina genome, most genes are present in three homeolog variants. LPEAT1 and LPEAT2 genes also have three homeologs each in C.sativa. Based on bioinformatiCs analyses we successfully amplified 5 different isoforms of CsLPEATs. Three of them had sequences highly similar to each CsLPEAT2 homeologs, present in the database of predicted C. sativa DH55 cultivar genes annotation. We named them: CsLPEAT2a, CsLPEAT2b, and CsLPEAT2c. In case of two other found sequences, the analysis revealed that they are variants of one homeolog, which we called CsLPEAT1a. The two variants were named accordingly CsLPEAT1a.1 and CsLPEAT1a.2. [45] 
In the conducted evolutionary analyses, we also took into account two other CsLPEAT1 isoforms, which we could not amplify from our cultivar's cDNA (CsLPEAT1b and CsLPEAT1c). The reason behind our inability to amplify these homeologs lies probably in high abundance of CsLPEAT1a variants in the cDNA. Regardless, the phylogenetic analysis itself revealed that both CsLPEAT1c and CsLPEAT2c originated from $C$. hispida genome with high probability. The other homeologs are likely derived from C. neglecta due to their calculated closer phylogenetic distance. Two of CsLPEAT1a isoform variants are highly similar, which influenced an insignificant bootstrap value for them. CsLPEAT1a variants differed only by one amino acid, however this difference was in close proximity to their respective LPE-binding domains. Phenylalanine in CsLPEAT1a.1 is substituted for cysteine in CsLPEAT1a.2. It is postulated that introduction of a polar sidechain, like in cysteine replacing a non-polar phenylalanine could have a significant effect on electrostatic and substrate-binding interactions [46]). The detected substitution may be the reason behind CsLPEAT1a variants exhibiting divergent lysophospholipid acyltransferase activities and biochemical properties. In the case of CsLPEAT2, we were able to amplify all three homeologs. Conserved domain analyses revealed that these isoforms all possessed additional calcium-binding domain, found also in AtLPEAT2 [16]. Both generated CsLPEAT1 and CsLPEAT2 trees revealed that CsLPEAT isoforms are more closely related to the other Brassicaceae LPEATs than to Arabidopsis LPLATs. 70\% similarity of the annotated genes was shown between $A$. thaliana and C. sativa by Kagale et al. [45].

Expression patterns for all CsLPEAT1 and CsLPEAT2 isoforms were determined for vegetative and generative organs. Among CsLPEAT1 isoforms, CsLPEAT1a, corresponding to its predicted variants CsLPEAT1a.1 and CsLPEAT1a.2, was the highest expressed isoform, whereas among CsLPEAT2 isoforms it was CsLPEAT2b. The lowest expressed isoform was CsLPEAT2c. Surprisingly, both mentioned CsLPEAT2 isoforms exhibited quite comparable specificities, despite the lack of activity towards 16:0-LPE by CsLPEAT2b. Such high similarities can be the reason for low expression of one of them. Relative expression patterns showed that CsLPEAT1 isoforms were more dominant than CsLPEAT2 in seeds in comparison to vegetative tissues. In vegetative tissues CsLPEAT1 and CsLPEAT2 expression was comparable, with leaves in vivo being the exception-CsLPEAT2b was more expressed there. Such dissimilarities in expression in different tissues are probably a result of various biochemical properties of PE from different tissues and function, which specific tissue plays in plant physiology. Absolute expression indicated that these isoforms are expressed at a quite comparable level in case of leaves and seeds. Studies conducted on other LPLAT enzymes showed remarkably low expression in C. sativa leaves compared to seeds [47]. It is worth to mention that the highest absolute expression of LPEAT genes was in roots, in which we also observed a very high activity of CsLPEAT enzymes. No correlation between expression levels and enzyme activity in in vitro leaves was noticed. In this tissue, all isoforms exhibited the lowest absolute expression, simultaneously displaying the highest activity of CsLPEAT enzymes present in plant microsomal fraction. The reason why in vitro cultivation conditions favored CsLPEAT enzymes activity remains to be elucidated in further studies.

\subsection{Biochemical CharacteristiCs and Temperature Susceptibility of CsLPEAT Enzymes}

Substrate specificity assays determining the impact of temperature on CsLPEATs activity were done towards five chosen acyl donors, which also represent most abundant fatty acids in PE of different $C$. sativa tissues: 16:0, 18:0, 18:1, 18:2, and 18:3. An analysis of fatty acids of $s n-1$ and $s n-2$ positions of PE of leaves also proved the presence of these acyl groups. In $s n-1$ position 16:0 dominated over other acyl groups, followed by unsaturated fatty acids. In $s n-2$ position a reverse pattern was observed. A similar composition of fatty acids in $s n-1$ position of PE was observed in $A$. thaliana leaves [37]. Nevertheless, the composition of molecular species of LPE in leaves constantly changed due to temperature alterations. In cold environment unsaturated fatty acids were present in LPE, whereas in heat stress, composition of fatty acids of LPE was quite similar to control conditions. 
16:0-LPE was the most abundant, followed by 18:2-LPE [34,37]. In seeds composition of LPE was very varied with prevailing amounts of 16:0-LPE. The second most abundant LPE was 18:1-LPE, which in some studies even exceeded 16:0-LPE content [48,49]. Thus, the variety of molecular species of LPE depends on cultivation conditions and tissue of origin. In our assays we used 16:0-LPE, 18:1-LPE and 18:2-LPE, which presence in C. sativa was confirmed.

Among all tested LPEAT isoforms and used acyl donors, the most efficient utilization was observed towards palmitic and stearic acids regardless of supplemented acyl acceptors. This result is unexpected, considering that in $s n-2$ position of phospholipids, created via eukaryotic pathway, the amount of saturated fatty acids is rather negligible [50]. However, in previous studies done by Stålberg et al. [16] and Jasieniecka-Gazarkiewicz et al. [24] the highest preference of AtLPEAT towards 16:0-CoA was detected. Moreover, in our study, we observed that LPEAT enzymes present in microsomal fractions of different tissues of C. sativa revealed strong preference towards $16: 0-\mathrm{CoA}$, especially in leaves. In the sn-2 position of PE about $10 \%$ of palmitic acid was detected. This LPEAT property may play an important role in heat stress by producing PE molecules possessing two palmitic acids, which would allow for maintaining the proper structure of phospholipid membranes in elevated temperatures. Palmitic acid is one of the compounds stabilizing membrane fluidity and its amount was shown to be rising when plants were subjected to heat stress $[35,37]$. This correlation was also observed in our assays. The preference towards 16:0-CoA of all CsLPEAT isoforms increased parallel with temperature.

CsLPEAT preferences, presented in assays with microsomal fraction from leaves (both in vivo and in vitro), roots and seeds clearly indicate that activity towards 18:3-CoA at $40{ }^{\circ} \mathrm{C}$ decreases or is similar to the activity detected at $30{ }^{\circ} \mathrm{C}$. The analysis conducted on microsomal fraction on yeast expressing different CsLPEAT isoforms did not always exhibit the same preferences. CsLPEAT1a.1 and CsLPEAT1a.2 activities towards 18:3-CoA decreased at $40^{\circ} \mathrm{C}$, compared to $30^{\circ} \mathrm{C}$. In case of CsLPEAT2 isoforms-CsLPEAT2a and CsLPEAT2c showed stable or only slightly higher activity, whereas activity of CsLPEAT2b increased by $35 \%$ at $40{ }^{\circ} \mathrm{C}$ in comparison to $30{ }^{\circ} \mathrm{C}$. Furthermore, the preferences towards 16:0-CoA where the highest in assays conducted with microsomal fractions derived from yeast, which was not the same for plant microsomes assays.

The observed discrepancies might be caused by the composition of lipid environment surrounding LPEAT enzymes, which may essentially influence their activity and substrate specificity. Also, each isoform might be expressed in a different manner at various temperatures, which could explain observed preferences of assays with microsomal fractions derived from plants.

This suggests that the results obtained from assays with yeast microsomal fractions elucidate mainly differences between the isoforms activity and substrate specificity. The potential physiological function of each isoform cannot be outright conjectured from these results. Here, the results from assays with plant microsomal fractions should be mainly considered as they showcase LPEAT activity in their native lipid environment.

VLCFA-rich PE species were so far detected in Arabidopsis thaliana leaves, roots and seeds [24,51,52]. In Camelina sativa the presence of gondoic acid (20:1) was detected, with its amount reaching 3.5\% in 18 DAF seeds [48]. Our study shows, that CsLPEAT2 exhibited a unique substrate specificity towards very-long-chain fatty acids (VLCFA). On the contrary, we did not observe overwhelming activity towards medium-chain, saturated fatty acids by CsLPEAT1. This was also previously observed for AtLPEAT isoforms [24]. The VLCFA are the dominant pool of acyl-CoA profile of C. sativa seeds [44,48]. Nevertheless, enzymes' preference towards them was detected on a negligible level assuming that they do not participate in G3P pathway leading to TAG synthesis in C. sativa seeds $[48,53]$. TAG synthesis supplementation via LPCAT activity, which may introduce fatty acids into the PC pool was examined in a study conducted by Klińska et al. [28], where LPCAT enzymes present in C. sativa seeds did not exhibit any activity, in forward reaction, towards these acyl donors. All these results clearly show that there must be another key player in this 
process, since mature seeds of $C$. sativa possess approximately $23-28 \%$ of VLCFA [28,54]. The biochemical properties of CsLPEAT2 isoforms indicate that they may be major players in transferring VLCFA to PE pool. VLCFA-rich PE could be thereafter transformed into PC pool via PEMTs activity and subsequently VLCFA could be transferred directly from $s n-2$ position of PE or PC to TAG pool via PDAT enzymes [17,55-57]. However, in such case C. sativa PDAT should be extremely specific towards VLCFA as only their small amounts were detected in PE and PC of C. sativa seeds [26,28].

Despite the high quantity of 16:0-LPE in plants, in each case, 16:0-LPE turned out to be the worst utilized acyl acceptor by all CsLPEAT isoforms. CsLPEAT2c did not exhibit any activity towards 18:2-CoA, while corresponding CsLPEAT2b activity equaled zero or was under the detection level also with other tested acyl-CoA. Decreased preferences towards 16:0-LPE, compared to 18:1-LPE, were previously noticed by Stålberg et al. [16] and Hishikawa et al. [58], both in case of 16:0-CoA or 18:1-CoA used as acyl donors. The biggest differences were observed for AtLPEAT2, which was also observed in our study. Another study determining selectivity of other LPLAT enzymes-LPAAT revealed that saturated lysophospholipids are not favored by these enzymes, unlike the tested 18:1-LPE [59]. The elevated content of 16:0-LPE characteristic for leaf membrane lipid composition may be explained by such enzyme's preference. These LPE species may be favored at elevated temperatures by CsLPEAT, which may correlate with adaptation and adjustment of phospholipid membrane for this biotic stress. To prove such property further investigations are needed.

The activity of both variants of CsLPEAT1a (CsLPEAT1a.1 and CsLPEAT1a.2), which were introduced into the yeast system, revealed generally higher preference towards tested acyl donors when 18:1-LPE was used as an acyl acceptor compared to assays with 18:2-LPE, at least in $30^{\circ} \mathrm{C}$. With 18:1-LPE, CSLPEAT1a was most specific towards saturated and monounsaturated acyl donors. The gene, which encoded this isoform was predominantly expressed in seeds, while the seed expression of CSLPEAT2 was significantly lower than in other tissues. Due to the governing presence of CsLPEAT1a in seeds its activity may be correlated with preference towards 18:1-LPE in this tissue. This molecular species of LPE is the second most abundant LPE in C. sativa seeds (after 16:0-LPE), between 18-24 DAF [48]. This period of seed development is characterized by the highest intensity of lipid accumulation [26,28]. Thus, it could be speculated that synthesized, via LPEAT action, PE is utilized by PDAT to transfer fatty acids from $s n-2$ position to DAG producing TAG (which is stored) and 18:1-LPE (which can be further reacylated via LPEAT action). However, high preferences of CSLPEAT1a towards saturated and monounsaturated fatty acids do not fit well with this hypothesis. The fatty acids incorporated into the seeds PE pool may be also transferred into PC pool. The PC can be formed from PE through three successive methylations by PE N-methyltransferases (PEMTs). Thus, PEMTs could be additional suppliers of monounsaturated fatty acids to PC pool. Subsequently PC-attached acyl groups can be desaturated. Unsaturated fatty acids are the dominant acyl compounds in C. sativa seeds $[28,48,55,57]$. However, so far not all PEMT enzymes needed for PE conversion to PC were identified in plants.

Contrary to both CsLPEAT1a isoform variants, which preferred utilization of 18:1LPE, each of CsLPEAT2 isoforms favored 18:2-LPE, as an acyl acceptor. Each isoform was able to incorporate all tested acyl donors into 18:2-LPE. CsLPEAT2c, followed by CsLPEAT2b, displayed the highest activity. Genes encoding these isoforms were the highest and the lowest expressed in vegetative tissues, respectively. Second-highest expressed gene was CsLPEAT1a, which preferred 18:1-LPE. The existence of enzymes with such various properties may be essentially connected with their expression in different plant tissues. Vegetative tissues are much more susceptible to external biotic conditions, which is why greater variability of acyl acceptors and donors may be needed to adapt to altered temperature conditions. Seeds possess additional protection of seed coats and siliques and are mainly responsible for lipid accumulation. 
CsLPEAT susceptibility to temperature, which we noticed in enzyme assays conducted in vitro with plant-derived microsomal fractions, was also confirmed for each individual cloned isoform introduced into the yeast system. In the yeast microsomal fraction assays, the 18:1-LPE were used as an acyl acceptor, because both CsLPEAT1 and CsLPEAT2 isoforms efficiently select this LPE type. Towards 16:0-CoA and 18:0-CoA the most active was CSLPEAT2c, regardless of temperature. The largest variability was observed when unsaturated fatty acids were used as acyl donors. At the lowest tested temperature 18:1CoA and 18:2-CoA were mainly utilized by CsLPEAT2a. This preference, however, changed with temperature increase. At $20^{\circ} \mathrm{C}$, CsLPEAT2c was the most active, whereas with further temperature rise, $C s L P E A T 2 b$ started to be the more active isoform. In lower temperatures 18:3-CoA was utilized by each CsLPEAT2 isoform with similar efficiency. The temperature rise favored CsLPEAT2b. In addition, other differences between isoforms and preferred acyl donors were detected. Observed CsLPEAT isoforms' behavior in correspondence with temperature fluctuations, supports our findings that these enzymes play a significant role in adaptation to cold and heat stress, through the adjustment of PE fatty acids composition and consequently membrane fluidity. Moreover, higher or lower expression of genes, encoding individual isoforms, may also correlate with temperature. Further studies are needed to verify this suggestion. Up until the presented study, no substrate specificity, selectivity, and activity assays at different temperatures were conducted for LPLAT enzymes. This work marks the first time that such an in-depth thermal and biochemical characterization of LPEAT enzymes was carried out.

\section{Materials and Methods}

\subsection{Chemicals}

Non-labelled acyl-CoA and radiolabelled $\left[{ }^{14} \mathrm{C}\right]$ acyl-CoA were synthesized from unlabelled fatty acids (Sigma-Aldrich, St. Louis, MO, USA) and ${ }^{14}$ C-labelled fatty acids (Perkin-Elmer) according to a modified method described by Sánchez et al. [60]. Other substrates for enzymes assays: non-labelled sn-1-18:1-lysophosphatidylethanolamine, sn1-18:1-lysophosphatidylcholine and lipid standards for thin-layer chromatography were purchased from Larodan Fine Chemicals and Avanti Polar Lipids, respectively.

\subsection{Plant Material and Growth Condition}

The analyzed plant material was derived from Camelina sativa L. Crantz, cv. Suneson. For obtaining plant material grown in in vivo, false flax seeds were planted in soil and cultivated in growth chamber at $23{ }^{\circ} \mathrm{C}$ with a photoperiod of $16 \mathrm{~h}$ of light $(120 \mathrm{mmol}$ photons $^{\mathrm{m}-2 \mathrm{~s}-1}$ ) $/ 8 \mathrm{~h}$ of dark with relative humidity of $60 \%$. The day when plants possessed well-developed flower buds, leaf materials were collected and after 24 days parts of their siliques were picked for further seed analysis.

To acquire material from the roots and leaves grown in vitro, C. sativa seeds were surface sterilized by immersion in $70 \%$ ethanol for 1 min followed by 10 min incubation in 3\% calcium hypochlorite. After that, the seeds were washed at least 3 times in distilled water and then planted on plates containing: $0.8 \%$ agar, $0.5 \times$ Murashige and Skoog (MS) medium and $2 \%$ sucrose. After 10 days, the seedlings were transferred into flasks with liquid $0.5 \times$ MS medium containing $2 \%$ sucrose and grown with shaking (100 rpm) for two more weeks at $23^{\circ} \mathrm{C}$.

\subsection{Gene Cloning and Sequence Analysis}

Putative LPEAT sequences were amplified using cDNA derived from developing tissues of C. sativa. Due to high similarity of sequences, to find every variant of LPEAT1 and LPEAT2, one pair of gene-specific primers, corresponding to each isoform, were used (Supplementary Table S2).

Phylogenetic tree construction of CSLPEAT isoforms and their variants were performed in MEGA X [61] with 1.000 bootstraps [62] in relation to Arabidopsis lyrata, Arabidopsis thaliana, Brassica napus, Brassica oleracea, Brassica rapa, Capsella rubella, Eutrema 
salsugineum, and Raphanus sativus. Their amino acid sequences were obtained from the NCBI databases. Sequence annotation was performed using CLC Main Workbench (Qiagen, Hilden, Germany).

\subsection{Vector Construction and Yeast Transformation}

CSLPEAT1 and CsLPEAT2 isoenzymes were cloned by Gateway cloning according to the manufacturer's protocol (Thermo Fisher, Waltham, MA, USA). The sequences were first incorporated into pDONR221 plasmids and then into pDEST52 plasmids containing a galactokinase 1 (GAL1) promoter.

Obtained pDEST52-GAL1::CsLPEAT constructs and an empty plasmid control were used for the transformation of Saccharomyces cerevisiae haploid knock-out mutants ALE1 (BY4741; Mat $\alpha$, his $3 \Delta 1$; leu2 $\Delta 0$; lys $2 \Delta 0$; ura $3 \Delta 0 ;$ YOR175c::kanMX4). The transformations of yeast were done according to the modified LiAc/SS carrier DNA/PEG method [63].

\subsection{Cleavage of Phosphatidylethanolamine by Phospholipase $A_{2}$}

Separation of phosphatidylethanolamine class was done according to the described by Klińska et al. [26], for which lipid extracts of 6-weeks old leaves from C. sativa were used. Individual lipid classes were visualized, on developed in polar solvent TLC plate, by a brief exposure to iodine vapours. Areas of the gel containing the PE, identified by means of authentic standards, were scraped off after the iodine has completely evaporated. Into the scraped gel fragments mixture of chloroform:methanol $(1: 2 ; \mathrm{v}: \mathrm{v})$ was added and sonicated for $15 \mathrm{~min}$. Extracted from gel PE fractions were collected to new probes and equal volumes of acetic acid, chloroform and water were added and centrifuged. The bottom, chloroform fraction containing PE was collected, dried under a stream of $\mathrm{N}_{2}$ and dissolved in $0.5 \mathrm{~mL}$ of diethyl ether. Subsequently, $1 \mathrm{~mL}$ of $0.1 \mathrm{M}$ Tris- $\mathrm{HCl}(\mathrm{pH}$ 8.9) with $5 \mathrm{mM} \mathrm{CaCl}_{2}$ and $3.3 \mathrm{U}$ of phospholipase $\mathrm{A}_{2}$ (derived from honeybee venom; Sigma-Aldrich, St. Louis, MO, USA) was added and vigorously stirred for $1 \mathrm{~h}$, to increase the surface contact between the water fraction in which phospholipase is present with the diethyl ether fraction containing PE. Reactions were stopped by supplementation of $20 \mu \mathrm{L}$ of acetic acid. To isolate only lipid fraction containing fatty acids and lysophospatidylethanolamine derived after PLA 2 activity, double Blight and Dyer (1959) [64] extraction method was applied. $3.75 \mathrm{~mL}$ of chloroform:methanol $(1: 2, v / v)$ followed by the addition of $1.25 \mathrm{~mL}$ of $0.15 \mathrm{M}$ acetic acid, $1.25 \mathrm{~mL}$ of chloroform and $1.25 \mathrm{~mL}$ of water were added to the samples. Collected, after centrifugation, chloroform fractions were separated by TLC on Silica gel 60 plates (Merck, Darmstadt, Germany) in chloroform:methanol:acetic acid:water (90:15:10:2.5, $v / v / v / v)$. Separated lipids: free fatty acids and lysophospatidylethanolamine, were visualized on the plate by water spraying. Areas of gel containing the LPE and free fatty acids were scraped off and methylated in situ on the gel with $2 \% \mathrm{H}_{2} \mathrm{SO}_{4}$ in dry methanol $\left(60 \mathrm{~min}\right.$ at $\left.90^{\circ} \mathrm{C}\right)$. The fatty acid methyl esters were extracted with hexane and the internal standard-methyl-heptadecanoate was added. Analysis of content and fatty acid composition of prepared samples was conducted by gas-liquid chromatography (Shimadzu; GC-2010) equipped with a fame ionization detector (FID) and a $60 \mathrm{~m} \times 0.25 \mathrm{~mm}$ CP-WAX 58-CB fused-silica column (Agilent Technologies, Santa Clara, CA, USA).

\subsection{Plant Microsomal Fraction Isolation and Enzyme Assay}

Microsomal membranes were prepared from freshly harvested tissues and isolations were done according to the method previously described [28] and stored at $-80{ }^{\circ} \mathrm{C}$ for further analysis. Determination of the microsomal fraction concentration was done by phosphatidylcholine (PC) and in some assays phosphatidylethanolamine (PE) content estimations. From the aliquots of derived microsomal fractions, lipid fractions were extracted by Blight and Dyer methods, described above. The chloroform fractions, containing lipids, were collected and separated for individual polar lipid classes by TLC in polar solvent. The plate with separated lipid classes was sprayed by $0.05 \%$ primuline solution and visualized under UV light. Based on used lipid standards, areas of gel containing the PC and PE were 
scraped off and methylated in situ on the gel with $2 \% \mathrm{H} 2 \mathrm{SO} 4$ in dry methanol (60 min at $90^{\circ} \mathrm{C}$ ). Derived fatty acid methyl esters were analyzed by gas chromatography as described in the previous paragraph.

Aliquots of microsomal isolates from in vivo leaves were subsequently used in in vitro optimization assays, to determine the best parameters for enzymatic reaction conducted by LPEAT-type enzymes present in vegetative tissue. The effect of various factors, such as reaction time, amount of microsomal fraction and buffer $\mathrm{pH}$ were examined in assays were $5 \mathrm{nmol}$ of $\left[{ }^{14} \mathrm{C}\right] 18: 1-\mathrm{CoA}$ and $5 \mathrm{nmol}$ of $\mathrm{sn}$-1-18:1-lysophosphatidylethanolamine were added. In case of seeds, the optimal parameters established by Klińska et. al. (2020) have been used.

Study focusing on activity and substrate specificity of LPEAT-type enzymes were performed with five $\left[{ }^{14} \mathrm{C}\right]$ acyl-CoAs: palmitoyl-CoA (16:0), stearoyl-CoA (18:0), oleoylCoA (18:1), linoleoyl-CoA (18:2) and linolenoyl-CoA (18:3). To each reactions $5 \mathrm{nmol}$ of sn-1-18:1-lysophosphatidylethanolamine (or sn-1-16:0-lysophosphatidylethanolamine, or sn-1-18:2-lysophosphatidylethanolamine, depending on conducted assays) and $5 \mathrm{nmol}$ of appropriate $\left[{ }^{14} \mathrm{C}\right]$ acyl-CoA were added. Final reaction mixture consisted of (in total volume of 100ul) $0.1 \mathrm{M}$ phosphate buffer ( $\mathrm{pH} 7.2$ ), $0.5 \mathrm{nmol}$ of microsomal PC equivalent to $2.2 \mu \mathrm{g}$ of microsomal proteins and in case of selectivity assay $2 \mathrm{mg} / \mathrm{mL}$ of BSA. Reactions were carried out for $60 \mathrm{~min}$ at $30^{\circ} \mathrm{C}$ (or in $10,20,40^{\circ} \mathrm{C}$ in assay determining substrate specificity at different temperature) in Eppendorf Thermomixer Compact with continuous shaking (1250 rpm). Termination of the reactions were done by adding $375 \mu \mathrm{L}$ chloroform/methanol $(1: 2 ; v / v), 5 \mu \mathrm{L}$ of glacial acetic acid, $125 \mu \mathrm{L}$ of chloroform and $125 \mathrm{ul}$ of water. Obtained chloroform fractions, containing lipids, were collected and separated on silica gel 60 plate by thin layer chromatography in polar solvent (chloroform/methanol/acetic acid/water; $90 / 15 / 10 / 2.5 ; v / v / v / v)$. The separated radiolabelled product of reaction was visualized and quantified by electronic autoradiography (Instant Imager, Packard Instrument Co., Meriden, CT, USA).

LPCAT activity assays were carried out in a similar manner. The only differences were: replacement of sn-1-18:1-LPE by sn-1-18:1-lysophosphatidylcholine, addition of aliquots of microsomal fraction containing $0.2 \mathrm{nmol}$ microsomal PC and $30 \mathrm{~min}$ of reaction time (optimal parameters established by Klińska et al. [28]).

The activity and acyl donor preference of LPEAT enzymes in the backward reaction assays were conducted with addition of $10 \mathrm{nmol}$ of $\left[{ }^{14} \mathrm{C}\right] \mathrm{acyl}-\mathrm{CoA}, 0.2 \mu \mathrm{mol}$ of free coenzyme $\mathrm{A}(\mathrm{CoA})$ and $1 \mathrm{mg}$ of BSA in a total volume of $100 \mu \mathrm{L}$ of $0.04 \mathrm{M}$ potassium bufer ( $\mathrm{pH}$ 7.2) with or without $0.5 \mu \mathrm{mol}$ of dithionitrobenzoic acid (DTNB). Reactions were conducted for $60 \mathrm{~min}$ at $30^{\circ} \mathrm{C}$, with addition of $5 \mathrm{nmol}$ of microsomal fractions. Calculation of backward reaction activity and estimation of the time of complete fatty acids turnover in PE pool were conducted according to (Jasieniecka-Gazarkiewicz et al. 2016; [20,28].

\subsection{Yeast Microsomal Preparation and Assay of CSLPEAT Isoforms Variant}

The transformed yeast cells carrying empty plasmid or plasmid with one of the tested LPEAT isoform genes were first cultured in uracil drop-out medium containing $2 \%$ of raffinose for $48 \mathrm{~h}$ at $30{ }^{\circ} \mathrm{C}$ on rotating platform (230rpm). Subsequently, these yeast cultures were used to inoculate $100 \mathrm{~mL}$ of fresh uracil drop-out medium with $2 \%$ of raffinose to an absorbance of $\mathrm{OD}_{600}$ of 0.2 and were cultivated for next 24h. After that time, the medium was supplemented by galactose to obtain a $2 \%$ final concentration and followed by $24 \mathrm{~h}$ incubation to induce gene expression and protein synthesis. Microsomal fractions were harvested as described Jasieniecka-Gazarkiewicz et.al. [20]. The aliquots of isolated microsomal fractions were examined to determine the phosphatidylcholine (PC) content for further enzymes essay.

Before determining the substrate specificity, the optimization was done for each of LPEAT isoform variants establishing the best time of reaction and amount of microsomal fractions. Further studies concentrated at substrate specificity towards various $\left[{ }^{14} \mathrm{C}\right]$ acyl-CoAs and the determination of activity of each of isoform variants at different 
temperatures, towards five chosen $\left[{ }^{14} \mathrm{C}\right] \mathrm{acyl}-\mathrm{CoAs}$ : palmitoyl-CoA, stearoyl-CoA, oleoylCoA, linoleoyl-CoA, and linolenoyl-CoA. Assays were conducted in a similar fashion as described above, except of reaction parameters, which were adapted from results of optimization analysis. Additional analyses determining the activity of CsLPEAT against sn-1-16:0-lysophosphatidylethanolamine and sn-1-18:2-lysophosphatidylethanolamine were done.

\subsection{Expression Analysis}

Primers for RT-qPCR can be found in Supplementary Table S3, along with their reference sequences. For this analysis, plants were cultivated as described in subsection 'Plant Material and Growth Condition'. Total RNA was extracted from all the tissues with GeneMatrix Universal RNA Purification Kit (EurX). Possible gDNA contamination was removed through incubation with dsDNase (Thermo Fisher Scientific). Maxima First Strand cDNA Synthesis Kit for RT-qPCR (Thermo Fisher Scientific, Waltham, MA, USA) was used to synthesize cDNA from RNA template. Desired cDNA fragments were amplified using Maxima SYBR Green/ROX qPCR Master Mix (2x; Thermo Fisher Scientific) in QuantStudioTM 3 Real-Time PCR System (Applied Biosystems, Waltham, MA, USA). For absolute expression analysis, amplicons of the investigated genes were purified with GeneJET PCR Purification Kit (Thermo Fisher Scientific). Serial dilutions of the amplicons were analyzed with qPCR to create amplification curves, which were later compared to particular genes' cDNA amplifications. Relative expression was conducted by applying the $2-\triangle \Delta C T$ algorithm [65]. CsLPEAT1a expression was treated as control, and all the results were normalized to either CsACT2 or CsTIP41 housekeeping genes. CsLPEAT amplicons were sequenced to confirm the primers' amplified desired genes.

\subsection{Sequence Comparison and Evolutionary Analysis}

References for amino acid sequences (others than the once isolated and sequenced by us) used in sequence alignments and evolutionary analyses can be found in Supplementary Table S4. The alignments presented in this publication were created in CLC Main Workbench 20 (Qiagen, Hilden, Germany). Domains and substrate-binding sites were found with NCBI Conserved Domain Search. The alignments for evolutionary analyses were created using ClustalW. The evolutionary histories were inferred by using the Maximum Likelihood method and JTT matrix-based model [66]. The bootstrap consensus trees inferred from 1000 replicates each [62] are taken to represent the evolutionary history of the taxa analyzed [62]. Branches corresponding to partitions reproduced in less than $50 \%$ bootstrap replicates are collapsed. The percentage of replicate trees in which the associated taxa clustered together in the bootstrap test (1000 replicates) are shown next to the branches [62]. Initial trees for the heuristic search were obtained automatically by applying Neighbor-Join and BioNJ algorithms to a matrix of pairwise distances estimated using the JTT model, and then selecting the topology with superior log likelihood value. LPEAT1 analysis involved 12 amino acid sequences and LPEAT2 analysis involved 11. There was a total of 466 positions in the final dataset for LPEAT1 analysis and 549 for LPEAT2 analysis. Evolutionary analyses were conducted in MEGA X [61].

\section{Conclusions}

Our study revealed that LPEAT enzymes substrate specificity can be modified by temperature. Moreover, we showed that each individual isoform of LPEAT enzymes has unique substrate preferences and the genes encoding these isoforms are showing different expression patterns in different tissues. All of this indicates that the role of LPEAT in plant metabolism and especially in phospholipid remodeling is very complex and can be regulated in many ways (including by environmental conditions). Existence of three isoforms of CsLPEAT1 and three isoforms of CsLPEAT2 has been shown. Sequence cloning allowed for detailed bioinformatiCs analyses including the determination of phylogenetic distance between each CsLPEAT isoform and revealed that CsLPEAT1c and CsLPEAT2c are 
more evolutionary-divergent from two other more-closely related homeologs. This finding suggests that these isoforms originated from C. hispida, whereas other isoforms originated from C. neglecta.

Supplementary Materials: The following are available online at https:/ / www.mdpi.com/article/10 $.3390 /$ ijms22158137/s1.

Author Contributions: All authors coordinated and designed the experiments. S.K., K.D. and K.J.-G. conducted the experiments. S.K., K.D. and A.B. drafted the manuscript. All authors have read and agreed to the published version of the manuscript.

Funding: The study was financed by National Science Centre, Poland; project OPUS 13. Project number: 2017/25/B/NZ3/00721.

Institutional Review Board Statement: Not applicable.

Informed Consent Statement: Not applicable.

Data Availability Statement: The data presented in this study are available on request from the corresponding authors. The data are not publicly available due to privacy.

Conflicts of Interest: The authors declare no conflict of interest.

\section{References}

1. Ruelland, E.; Vaultier, M.N.; Zachowski, A.; Hurry, V. Cold signalling and cold acclimation in plants. Adv. Bot. Res. 2009, 49, 35-150.

2. Kates, M.; Pugh, E.L.; Ferrante, G. Regulation of membrane fluidity by lipid desaturases. Biomembranes 1984, 12, 379-395.

3. Vinocur, B.; Altman, A. Recent advances in engineering plant tolerance to abiotic stress: Achievements and limitations. Curr. Opin. Biotechnol. 2005, 16, 123-132. [CrossRef] [PubMed]

4. Narayanan, S. Effects of high temperature stress and traits associated with tolerance in wheat. Open Access J. Sci. 2018, 2, 177-186. [CrossRef]

5. Mason, J.T. Investigation of phase transitions in bilayer membranes. Methods Enzymol. 1998, 295, 468-494. [PubMed]

6. De Kroon, A.I.P.M. Metabolism of phosphatidylcholine and its implications for lipid acyl chain composition in Saccharomyces cerevisiae. Biochim. Biophys. Acta 2007, 1771, 343-352. [CrossRef]

7. Christie, W.W.; Han, X. Lipids: Their structures and occurrence. Lipid Anal. 2012, 1, 3-19.

8. De Kruijff, B. Lipid polymorphism and biomembrane function. Curr. Opin. Chem. Biol. 1997, 1, 564-569. [CrossRef]

9. Birner, R.; Bürgermeister, M.; Schneiter, R.; Daum, G. Roles of phosphatidylethanolamine and of its several biosynthetic pathways in Saccharomyces cerevisiae. Mol. Biol. Cell 2001, 12, 997-1007. [CrossRef] [PubMed]

10. Momchilova, A.; Markovska, T. Phosphatidylethanolamine and phosphatidylcholine are sources of diacylglycerol in rastransformed NIH 3 T3 fibroblasts. Int. J. Biochem. Cell Biol. 1999, 31, 311-318. [CrossRef]

11. Rockenfeller, P.; Koska, M.; Pietrocola, F.; Minois, N.; Knittelfelder, O.; Sica, V.; Franz, J.; Carmona-Gutierrez, D.; Kroemer, G.; Madeo, F. Phosphatidylethanolamine positively regulates autophagy and longevity. Cell Death Differ. 2015, 22, 499-508. [CrossRef] [PubMed]

12. D'Herde, K.; Krysko, D.V. Ferroptosis: Oxidized PEs trigger death. Nat. Chem. Biol. 2017, 13, 4-5. [CrossRef] [PubMed]

13. Eto, M.; Shindou, H.; Yamamoto, S.; Tamura-Nakano, M.; Shimizu, T. Lysophosphatidylethanolamine acyltransferase 2 (LPEAT2) incorporates DHA into phospholipids and has possible functions for fatty acid-induced cell death. Biochem. Biophys. Res. Commun. 2020, 526, 246-252. [CrossRef] [PubMed]

14. Kennedy, E.P.; Weiss, S.B. The function of cytidine coenzymes in the biosynthesis of phospholipides. J. Biol. Chem. 1956, 222, 193-214. [CrossRef]

15. Nerlich, A.; von Orlow, M.; Rontein, D.; Hanson, A.D.; Dörmann, P. Deficiency in phosphatidylserine decarboxylase activity in the psd1 psd2 psd3 triple mutant of Arabidopsis affects phosphatidylethanolamine accumulation in mitochondria. Plant Physiol. 2007, 144, 904-914. [CrossRef]

16. Stålberg, K.; Ståhl, U.; Stymne, S.; Ohlrogge, J. Characterization of two Arabidopsis thaliana acyltransferases with preference for lysophosphatidylethanolamine. BMC Plant Biol. 2009, 9, 60. [CrossRef]

17. Ståhl, U.; Stålberg, K.; Stymne, S.; Ronne, H. A family of eukaryotic lysophospholipid acyltransferases with broad specificity. FEBS Lett. 2008, 582, 305-309. [CrossRef]

18. Bates, P.D.; Fatihi, A.; Snapp, A.R.; Carlsson, A.S.; Browse, J.; Lu, C. Acyl Editing and Headgroup Exchange Are the Major Mechanisms That Direct Polyunsaturated Fatty Acid Flux into Triacylglycerols. Plant Physiol. 2012, 160, 1530-1539. [CrossRef] [PubMed]

19. Lager, I.; Yilmaz, J.L.; Zhou, X.R.; Jasieniecka, K.; Kazachkov, M.; Wang, P.; Zou, J.; Weselake, R.; Smith, M.A.; Bayon, S.; et al. Plant acyl-CoA:lysophosphatidylcholine acyltransferases (LPCATs) have different specificities in their forward and reverse reactions. J. Biol. Chem. 2013, 288, 36902-36914. [CrossRef] 
20. Jasieniecka-Gazarkiewicz, K.; Demski, K.; Lager, I.; Stymne, S.; Banaś, A. Possible role of different yeast and plant lysophospholipid:acyl-CoA acyltransferases (LPLATs) in acyl remodelling of phospholipids. Lipids 2016, 51, 15-23. [CrossRef]

21. Lands, W.E. Metabolism of glycerolipides; a comparison of lecithin and triglyceride synthesis. J. Biol. Chem. 1958, 231, 883-888. [CrossRef]

22. Dahlqvist, A.; Ståhl, U.; Lenman, M.; Banaś, A.; Lee, M.; Sandager, L.; Ronne, H.; Stymne, S. Phospholipid:diacylglycerol acyltransferase: An enzyme that catalyzes the acylCoA-independent formation of triacylglycerol in yeast and plants. Proc. Natl. Acad. Sci. USA 2000, 97, 6487-6492.

23. Tasseva, G.; Richard, L.; Zachowski, A. Regulation of phosphatidylcholine biosynthesis under salt stress involves choline kinases in Arabidopsis thaliana. FEBS Lett. 2004, 566, 115-120. [CrossRef] [PubMed]

24. Jasieniecka-Gazarkiewicz, K.; Lager, I.; Carlsson, A.S.; Gutbrod, K.; Peisker, H.; Dörmann, P.; Stymne, S.; Banaś, A. Acylcoa:Lysophosphatidylethanolamine acyltransferase activity regulates growth of Arabidopsis. Plant Physiol. 2017, 174, 986-998. [CrossRef]

25. Jasieniecka-Gazarkiewicz, K.; Demski, K.; Gidda, S.K.; Klińska, S.; Niedojadło, J.; Lager, I.; Carlsson, A.S.; Minina, E.A.; Mullen, R.T.; Bozhkov, P.V.; et al. Subcellular localization of acyl-CoA: Lysophosphatidylethanolamine acyltransferases (LPEATs) and the effects of knocking-out and overexpression of their genes on autophagy markers level and life span of A. thaliana. Int. J. Mol. Sci. 2021, 22, 3006. [CrossRef] [PubMed]

26. Klińska, S.; Jasieniecka-Gazarkiewicz, K.; Demski, K.; Banaś, A. Editing of phosphatidic acid and phosphatidylethanolamine by acyl-CoA: Lysophospholipid acyltransferases in developing Camelina sativa seeds. Planta 2020, 10, 4. [CrossRef]

27. Martinière, A.; Bassil, E.; Jublanc, E.; Alcon, C.; Reguera, M.; Sentenac, H.; Blumwald, E.; Paris, N. In vivo intracellular pH measurements in tobacco and Arabidopsis reveal an unexpected $\mathrm{pH}$ gradient in the endomembrane system. Plant Cell 2013, 25, 4028-4043. [CrossRef] [PubMed]

28. Klińska, S.; Jasieniecka-Gazarkiewicz, K.; Banaś, A. Acyl-CoA: Lysophosphatidylcholine acyltransferases (LPCATs) of Camelina sativa seeds: Biochemical properties and function. Planta 2019, 250, 1655-1670. [CrossRef] [PubMed]

29. Mandáková, T.; Pouch, M.; Brock, J.R.; Al-Shehbaz, I.A.; Lysak, M.A. Origin and Evolution of Diploid and Allopolyploid Camelina Genomes Were Accompanied by Chromosome Shattering. Plant Cell 2019, 31, 2596-2612.

30. Search for Conserved Domains within a Protein or Coding Nucleotide Sequence. Available online: https://www.ncbi.nlm.nih. gov/Structure/cdd/wrpsb.cgi (accessed on 4 May 2021).

31. Canvin, D.T. The effect of temperature on the oil content and fatty acid composition of oils from several oil seed crops. Can. J. Bot. 1965, 43, 63-69. [CrossRef]

32. Wolf, R.B.; Cavins, J.F.; Kleiman, R.; Black, L.T. Effect of temperature on soybean seed constituents: Oil, protein, moisture, fatty acids, amino acids and sugars. J. Am. Oil Chem. Soc. 1982, 59, 230-232. [CrossRef]

33. Schulte, L.R.; Ballard, T.; Samarakoon, T.; Yao, L.; Vadlani, P.; Staggenborg, S.; Rezac, M. Increased growing temperature reduces content of polyunsaturated fatty acids in four oilseed crops. Industrial Crops Prod. 2013, 51, 212-219. [CrossRef]

34. Welti, R.; Li, W.; Li, M.; Sang, Y.; Biesiada, H.; Zhou, H.E.; Rajashekar, C.B.; Williams, T.D.; Wang, X. Profiling membrane lipids in plant stress responses. Role of phospholipase D alpha in freezing-induced lipid changes in Arabidopsis. J. Biol. Chem. 2002, 277, 31994-32002. [CrossRef]

35. Falcone, D.L.; Ogas, J.P.; Somerville, C.R. Regulation of membrane fatty acid composition by temperature in mutants of Arabidopsis with alterations in membrane lipid composition. BMC Plant Biol. 2004, 4, 17. [CrossRef]

36. Saidi, Y.; Peter, M.; Finka, A.; Cicekli, C.; Vigh, L.; Goloubinoff, P. Membrane lipid composition affects plant heat sensing and modulates $\mathrm{Ca}^{2+}$-dependent heat shock response. Plant Signal. Behav. 2010, 5, 1530-1533. [CrossRef]

37. Qin, F.; Lin, L.; Jia, Y.; Li, W.; Yu, B. Quantitative Profiling of Arabidopsis Polar Glycerolipids under Two Types of Heat Stress. Plants 2020, 9, 693. [CrossRef]

38. Williams, J.P.; Khan, M.U.; Mitchell, K.; Johnson, G. The Effect of Temperature on the Level and Biosynthesis of Unsaturated Fatty Acids in Diacylglycerols of Brassica napus Leaves. Plant Physiol. 1988, 87, 904-910. [CrossRef]

39. Murakami, Y.; Tsuyama, M.; Kobayashi, Y.; Kodama, H.; Iba, K. Trienoic Fatty Acids and Plant Tolerance of High Temperature. Science 2000, 287, 476-479. [CrossRef] [PubMed]

40. Yuan, L.; Mao, X.; Zhao, K.; Ji, X.; Ji, C.; Xue, J.; Li, R. Characterisation of phospholipid: Diacylglycerol acyltransferases (PDATs) from Camelina sativa and their roles in stress responses. Biol. Open. 2017, 6, 1024-1034. [CrossRef]

41. Stymne, S.; Stobart, A.K. The biosynthesis of triacylglycerols in microsomal preparations of developing cotyledons of sunfower (Helianthus annuus L.). Biochem. J. 1984, 220, 481-488. [CrossRef] [PubMed]

42. Engeseth, N.J.; Pacovskya, R.S.; Newman, T.; Ohlrogge, J.B. Characterization of an acyl-CoA-binding protein from Arabidopsis thaliana. Arch. Biochem. Biophys. 1996, 331, 55-62. [CrossRef] [PubMed]

43. Li-Beisson, Y.; Shorrosh, B.; Beisson, F.; Andersson, M.X.; Arondel, V.; Bates, P.D.; Baud, S.; Bird, D.; DeBono, A.; Durrett, T.P.; et al. Acyl-Lipid Metabolism. Arab. Book 2013, 11, e0161. [CrossRef] [PubMed]

44. Ruiz-Lopez, N.; Broughton, R.; Usher, S.; Salas, J.J.; Haslam, R.P.; Napier, J.A.; Beaudoin, F. Tailoring the composition of novel wax esters in the seeds of transgenic Camelina sativa through systematic metabolic engineering. Plant Biotechnol. J. 2017, 15, 837-849. [CrossRef] [PubMed] 
45. Kagale, S.; Koh, C.; Nixon, J.; Bollina, V.; Clarke, W.E.; Tuteja, R.; Spillane, C.; Robinson, S.J.; Links, M.G.; Clarke, C.; et al. The emerging biofuel crop Camelina sativa retains a highly undifferentiated hexaploid genome structure. Nat. Commun. 2014, 5, 3706. [CrossRef]

46. Roberts, J.A.; Digby, H.R.; Kara, M.; El Ajouz, S.; Sutcliffe, M.J.; Evans, R.J. Cysteine substitution mutagenesis and the effects of methanethiosulfonate reagents at P2X2 and P2X4 receptors support a core common mode of ATP action at P2X receptors. J. Biol. Chem. 2008, 283, 20126-20136. [CrossRef]

47. Abdullah, H.M.; Akbari, P.; Paulose, B.; Schnell, D.; Qi, W.; Park, Y.; Pareek, A.; Dhankher, O.P. Transcriptome profiling of Camelina sativa to identify genes involved in triacylglycerol biosynthesis and accumulation in the developing seeds. Biotechnol. Biofuels. 2016, 9, 136. [CrossRef] [PubMed]

48. Marmon, S.; Sturtevant, D.; Herrfurth, C.; Chapman, K.; Stymne, S.; Feussner, I. Two Acyltransferases Contribute Differently to Linolenic Acid Levels in Seed Oil. Plant Physiol. 2017, 173, 2081-2095. [CrossRef] [PubMed]

49. Abdullah, H.M.; Chhikara, S.; Akbari, P.; Schnell, D.J.; Pareek, A.; Dhankher, O.P. Comparative transcriptome and metabolome analysis suggests bottlenecks that limit seed and oil yields in transgenic Camelina sativa expressing diacylglycerol acyltransferase 1 and glycerol-3-phosphate dehydrogenase. Biotechnol. Biofuels. 2018, 11, 335. [CrossRef]

50. Lightner, J.; Wu, J.; Browse, J. A mutant of Arabidopsis with increased levels of stearic acid. Plant Physiol. 1994, 106, 1443-1451. [CrossRef]

51. Maatta, S.; Scheu, B.; Roth, M.R.; Tamura, P.; Li, M.; Williams, T.D.; Wang, X.; Welti, R. Levels of Arabidopsis thaliana Leaf Phosphatidic Acids, Phosphatidylserines, and Most Trienoate-Containing Polar Lipid Molecular Species Increase during the Dark Period of the Diurnal Cycle. Front. Plant Sci. 2012, 3, 49. [CrossRef]

52. Zhou, X.R.; Callahan, D.L.; Shrestha, P.; Liu, Q.; Petrie, J.R.; Singh, S.P. Lipidomic analysis of Arabidopsis seed genetically engineered to contain DHA. Front. Plant Sci. 2014, 5, 419. [CrossRef]

53. Lager, I.; Jeppson, S.; Gippert, A.L.; Feussner, I.; Stymne, S.; Marmon, S. Acyltransferases Regulate Oil Quality in Camelina sativa Through Both Acyl Donor and Acyl Acceptor Specificities. Front. Plant Sci. 2020, 11, 1144. [CrossRef] [PubMed]

54. Rodríguez-Rodríguez, M.F.; Sánchez-García, A.; Salas, J.J.; Garcés, R.; Martínez-Force, E. Characterization of the morphological changes and fatty acid profile of developing Camelina sativa seeds. Ind. Crops Prod. 2013, 50, 673-679. [CrossRef]

55. Rhodes, D.; Hanson, A.D. Quaternary ammonium and tertiary sulfonium compouns in higher plants. Annu. Rev. Plant Physiol. Plant Mol. Biol. 1993, 44, 357-384. [CrossRef]

56. Banaś, A.; Dahlqvist, A.; Ståhl, U.; Lenman, M.; Stymne, S. The involvement of phospholipid:diacylglycerol acyltransferases in triacylglycerol production. Biochem. Soc. Trans. 2000, 28, 703-705. [CrossRef] [PubMed]

57. Kwon, Y.; Yu, S.I.; Lee, H.; Yim, J.H.; Zhu, J.K.; Lee, B.H. Arabidopsis serine decarboxylase mutants implicate the roles of ethanolamine in plant growth and development. Int. J. Mol. Sci. 2012, 13, 3176-3188. [CrossRef]

58. Hishikawa, D.; Shindou, H.; Kobayashi, S.; Nakanishi, H.; Taguchi, R.; Shimizu, T. Discovery of a lysophospholipid acyltransferase family essential for membrane asymmetry and diversity. Proc. Natl. Acad. Sci. USA 2008, 105, 2830-2835. [CrossRef] [PubMed]

59. Oo, K.C.; Huang, A.H. Lysophosphatidate acyltransferase activities in the microsomes from palm endosperm, maize scutellum, and rapeseed cotyledon of maturing seeds. Plant Physiol. 1989, 91, 1288-1295. [CrossRef] [PubMed]

60. Sánchez, M.; David, G.N.; David, N.B. The relationship between palmitoyl-coenzyme A synthetase activity and esterification of sn-glycerol 3-phosphate in rat liver mitochondria. Biochem. J. 1973, 132, 697-706. [CrossRef] [PubMed]

61. Kumar, S.; Stecher, G.; Li, M.; Knyaz, C.; Tamura, K. MEGA X: Molecular Evolutionary GenetiCs Analysis across computing platforms. Mol. Biol. Evol. 2018, 35, 1547-1549. [CrossRef] [PubMed]

62. Felsenstein, J. Confidence limits on phylogenies: An approach using the bootstrap. Evolution 1985, 39, 783-791. [CrossRef] [PubMed]

63. Gietz, R.D.; Woods, R.A. Transformation of yeast by lithium acetate/single-stranded carrier DNA/polyethylene glycol method. Methods Enzymol. 2002, 350, 87-96. [PubMed]

64. Bligh, E.G.; Dyer, W.J. A rapid method of total lipid extraction and purification. Can. J. Biochem. Physiol. 1959, 37, 911-917. [CrossRef] [PubMed]

65. Winer, J.; Jung, C.K.; Shackel, I.; Williams, P.M. Development and validation of real-time quantitative reverse transcriptasepolymerase chain reaction for monitoring gene expression in cardiac myocytes in vitro. Anal. Biochem. 1999, 270, 41-49. [CrossRef] [PubMed]

66. Jones, D.T.; Taylor, W.R.; Thornton, J.M. The rapid generation of mutation data matrices from protein sequences. BioinformatiCs 1992, 8, 275-282. [CrossRef] [PubMed] 